Article

\title{
An Interdisciplinary Approach to the Sustainable Management of Territorial Resources in Hodh el Chargui, Mauritania
}

\author{
Chiara Caselle ${ }^{1, *(\mathbb{D})}$, Sabrina Maria Rita Bonetto ${ }^{1}$, Domenico Antonio De Luca ${ }^{1}$, \\ Manuela Lasagna ${ }^{1}\left(\right.$, Luigi Perotti ${ }^{1}\left({ }\right.$, Arianna Bucci ${ }^{2}$ and Stefano Bechis ${ }^{3}$ \\ 1 Department of Earth Science, University of Torino, 10125 Torino, Italy; sabrina.bonetto@unito.it (S.M.R.B.); \\ domenico.deluca@unito.it (D.A.D.L.); manuela.lasagna@unito.it (M.L.); luigi.perotti@unito.it (L.P.) \\ 2 Geodata Engineering S.p.A., Corso Bolzano 14, 10121 Torino, Italy; aria.bucci@gmail.com \\ 3 Interuniversity Department of Regional and Urban Studies and Planning (DIST), Politecnico and University \\ of Torino, 10125 Torino, Italy; stefano.bechis@unito.it \\ * Correspondence: chiara.caselle@unito.it
}

Received: 28 May 2020; Accepted: 17 June 2020; Published: 23 June 2020

check for updates

\begin{abstract}
The present study proposes an analytical investigation of the natural resources and social framework of the Hodh el Chargui region (Mauritania), aiming to offer a useful instrument for planning and management to the local authorities. The situation of the region was evaluated by means of a participatory survey carried out among the local inhabitants. The obtained results include a collection of data about population, territorial organization, access to basic education and health services, infrastructure, main economic activities, and natural resources (in terms of water, both surface and groundwater, duration and intensity of rainfalls, soil types, and vegetal resources). The survey outcomes were completed with an integrated approach based on Earth Observation (EO) data supports, such as digital elevation models (DEMs) and Landsat8 imagery. The interdependence among the different data was evaluated and discussed, with regard to the influence of the availability of natural resources on the development of agricultural activities and on the general social welfare. The results are organized in the form of digital maps and a user-friendly webmap platform to facilitate access for all the technical and nontechnical actors involved in the project.
\end{abstract}

Keywords: natural resources; Mauritania; resource management; regional planning; participatory approach; EO data

\section{Introduction}

The regional planning and management of natural resources require us to consider the interactions among human needs, ecosystem dynamics and resource sustainability, keeping a balance between the different elements. In particular, in tropical rural or semirural areas of sub-Saharan Africa, the shortage of natural resources requires specific attention to correct planning and a proper direction of the interventions [1-4]. In these areas, the frequent drought periods, the ephemeral nature of surface water and the poorness of natural vegetation often generate severe risk scenarios. In addition, the vulnerability of rural and agro-pastoral communities living in these environments is often high due to the low adequacy of infrastructure that should provide access to the basic needs of the population (e.g., water, health care, education, transport).

The assessment of natural resource availability and sustainable use is, however, insufficient to carry out a correct decision-making and intervention process that should also include the evaluation of social, economic and cultural factors [5,6]. 
At a regional scale, the identification of more exposed communities, with suggestions on how to deal with risks, could help the proper direction of aid, helping the local authorities in risk-informed decision-making that favours the sustainable development of the territory. An effective planning process requires the combined consideration of environmental, technological, economic and socio-political factors.

With these purposes, the European Project "Renforcement Institutionnel en Mauritanie vers la Résilience Agricole \& Pastorale" (RIMRAP) developed an interdisciplinary approach for the assessment of the vulnerability to risk of the population in Mauritania, with the aim of facilitating risk-informed intervention planning. The present study proposes a review of the results obtained in the analysis of southeastern Wilaya (Region), denominated as Hodh el Chargui (Figure 1).

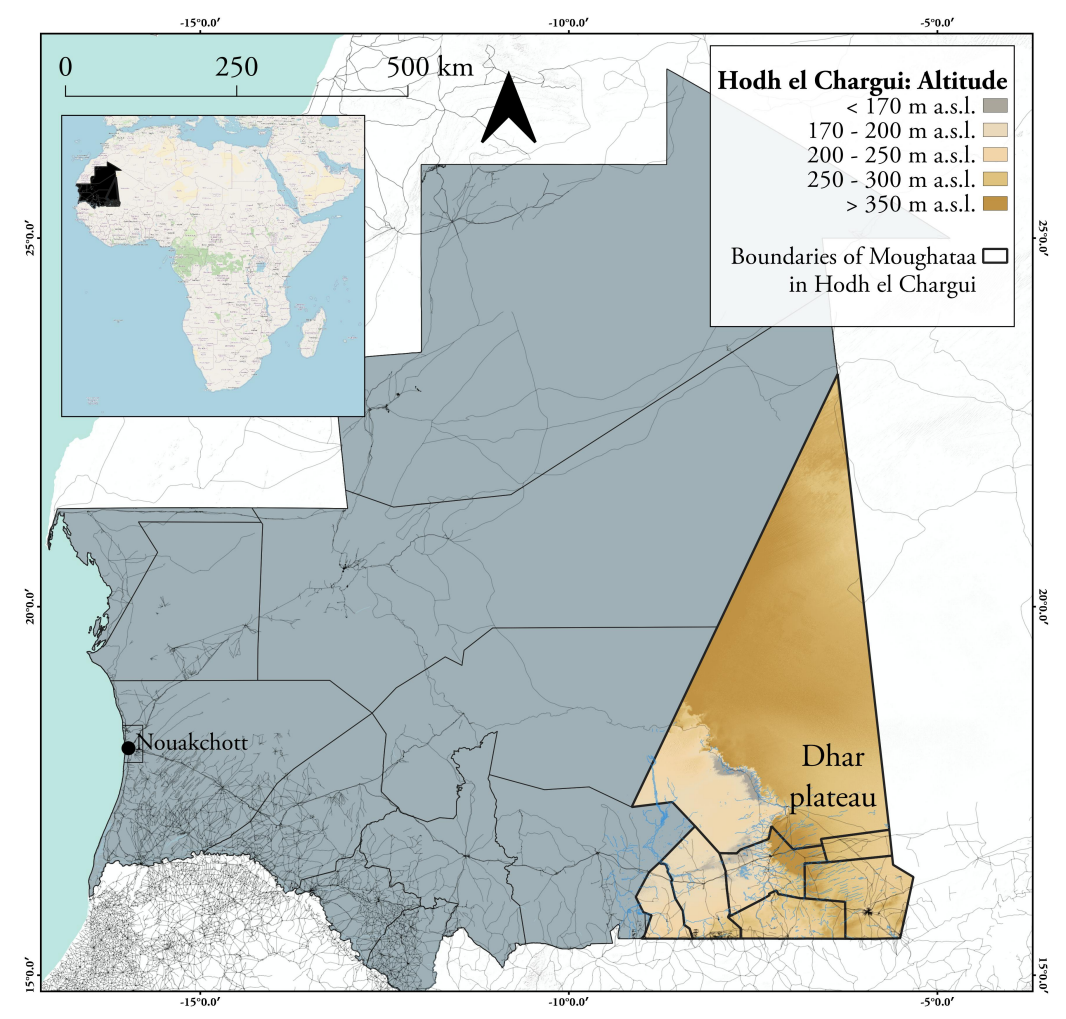

Figure 1. Location of the Hodh el Chargui region in southeastern Mauritania.

The region, one of the poorest and most remote of Mauritania, is located about $1000 \mathrm{~km}$ east of the capital city, Nouakchott. As a consequence, the area suffers from weaknesses in public investments and, hence, of basic social services (e.g., schools and health centres), transport and communications. The administrative organization sees a division in 7 Moughataa (Provinces), subdivided, in turn, into 31 minor territorial units (municipalities). The area is mainly rural, being occupied by small villages (communities) inhabited by both nomadic and settled people, whose principal activities are pastoralism and, only secondarily, agriculture [7].

From a morphological point of view, the territory is characterised, in the northeastern part, by a high plateau (Dhar Plateau), with maximum heights of $420 \mathrm{~m}$ above sea level (a.s.l. in all the maps). The western cliff of the plateau delimitates a large flat area, with altitudes ranging between 150 and $250 \mathrm{~m}$ a.s.l., which corresponds to the most lively and actively populated part of the region.

The area is mainly covered by sand dunes, especially in the north of the region, where the aeolian deposits may reach thicknesses of more than $100 \mathrm{~m}$. In the south of the region, the thicknesses are lower, and the deposits are mainly fixed dune fields extended in an ENE-WSW direction that progressively leave their place to the emerging rocky basement. The surface water resources of the region mainly 
consist of wadis, which, during the dry season, dry-up, leaving only sanded riverbeds. Very often, they are subject to an enlargement of the riverbed and to the erosion of the banks caused by occasional intensive precipitation and by degraded vegetation cover $[8,9]$.

The climate is controlled by a seasonal alternation, with a long dry season (from October to June) and a short humid season (from July to September), with rainy precipitations that may sometimes be violent and catastrophic.

The hard climatic conditions and the poor development of agricultural activities imply a low coverage of cereal needs (on average, $30 \%$ of needs) and considerable imports of rice, oil, wheat flour and other commodities. This affects the country's balance of payments and exposes it to risks of external crisis. In addition, the rural exodus deprives the countryside of manpower and prevents the execution of the traditional mechanisms of development, maintenance and conservation of these fragile ecosystems, threatening the livelihoods of rural populations in these areas, undermining their resilience and exacerbating conflicts for natural resources $[7,10]$.

The present study aims to approach this reality and create a reliable and accurate cartographical representation of the demographical, administrative, socio-economic features and availability of natural resources. The objective is to create a realistic framework of the human and natural resources in the Hodh el Chargui, in order to provide a reliable reference point to the local authorities for risk-informed planning of the interventions. The approach involved onsite data collection through a participatory survey proposed to the local inhabitants. The results of the survey were integrated and completed with the help of data retrieved with Earth Observation techniques.

\section{Materials and Methods}

\subsection{Onsite Survey}

The onsite survey was conducted with a participative approach, involving the local inhabitants, in order to obtain diffuse information on the local conditions. A specific questionnaire was developed, including inquiries on the population (total number and repartition between women and men), the percentage of literate people, the type of habitations, the infrastructures for water, energy, health, education, transportation and telecommunications, and the principal economic activities, with specific attention to pastoralism and agriculture. Besides this information, a more specific set of questions was directed to the analysis of natural resources, considering the duration of the rainy season, the perception of the climatic changes in the last 20 years and the features of soil, vegetal resources and water (surface and groundwater). This general questionnaire was recalibrated for the survey of the 31 municipalities and of all agro-pastoral communities with at least 300 inhabitants. In the former case, the survey was conducted in the chief towns, collecting information about the entire area of the municipalities. In the latter case, the survey is more specifically referred to as the single community, allowing for a capillary reconstruction of the features of the region. The complete question forms may be found in Supplementary Materials S1 and S2.

In addition, a specific questionnaire was prepared for the investigation of the features of water wells in the area (Supplementary Material S3); this survey was specifically aimed at the reconstruction of groundwater characteristics and their accessibility and governance. The collected information was completed and integrated with the available literature data that included similar surveys on the wells of the region $[8,11]$.

\subsection{Integration of Collected Information with EO Data}

Despite the large distribution of the communities on the territory of the Hodh el Chargui, the data collected with the onsite survey only provided specific information. To complete the framework about the distribution on natural resources in the region, data were integrated through the analysis and interpretation of USGS (United States Geological Survey) Landsat imagery and with digital elevation models (DEMs) of the region. 
More in detail, the Landsat images were standard Landsat- 8 operational land imager (OLI) data products, radiometrically and geometrically corrected and referred to as Level-1TP (L1TP). The L1TP products are digital numbers with coefficients provided to convert data to either radiance or reflectance. The images, obtained from USGS Landsat collection service, are considered suitable for time-series analysis. The georegistration is indeed consistent and within prescribed tolerances $(<12 \mathrm{~m}$ root mean square error - RMSE). The downloaded images are radiometrically calibrated and orthorectified, using ground control points (GCPs) and digital elevation model (DEM) data to correct relief displacement. GCPs were derived from the Global Land Survey 2000 (GLS2000) dataset. The onboard sensor reflective operational land imager (OLI) bands are 30-m resolution, and DNs are stored as 16-bit signed integers that can be linearly scaled to the top of atmosphere (TOA) reflectance. The selected images were acquired on 11 September 2015 for the rainy season and 15 April 2019 for the dry season, and their positions correspond to 199-049 and 200-049 of the Landsat repository. The Landsat-8 L1TP image digital numbers for each band were converted to top of atmosphere (TOA) reflectance, using the scaling factors stored in the metadata using QGIS SCP (semiclassification plugin, free version). Finally, dark subtraction with dark object minimum atmospheric correction was applied in order to obtain final surface reflectance Landsat 8 band stacks [12].

The DEM was the USGS EROS Archive Digital Elevation Model-Shuttle Radar Topography Mission (SRTM) - 1 Arc-Second Global version, obtained from USGS EarthExplorer. The Shuttle Radar Topography Mission (SRTM) was flown aboard the space shuttle Endeavour 11 on 22 February 2000. The SRTM elevation data offer worldwide coverage of void-filled data at a resolution of 1 arc-second $(30 \mathrm{~m})$ and provide open distribution of this high-resolution global dataset [13,14].

These data were analysed and interpreted to obtain:

- a cartographic base for specific data collection and interpretation;

- hydrological analysis of the surface water finalised to the creation of a watershed basins map;

- a reconstruction of the land use of the project area, focusing on vegetation cover in different seasons.

The automatic or semiautomatic definition of watershed basins starting from a DEM is a common practice in the GIS applicative world. However, particular cases as large flat areas, with complex river networks, flat terrains, crossed and looped channels and a large number of polders may create complex hydrographic conditions that make it impossible to accomplish automatic river network extraction and watershed delineation by using DEMs with automatic processes [15-17]. To face this problem, a specific procedure was developed, including the first phase of manual delineation of a river network, using as input the available literature-e.g., historical sources, reports, maps-and the USGS Landsat8 images. The second phase of the procedure consisted of a semiautomatic watershed definition with the ArcGis Watershed Delineation Tool $[18,19]$ based on the DEM and the manually delineated river network. Results were then attentively checked to verify the correspondence between the automatic result and the real morphology suggested by the Landsat images.

For the analysis of the vegetation and the creation of the use of land maps, the Semiautomatic Classification QGIS plugin [20] was employed. The method requires the definition of reference areas with known land cover features that are used by the software to train the classification algorithm. In this application, we took as reference the data about natural vegetation from the surveys in the communities, using the Spectral Angle Map algorithm, with a threshold angle of $20^{\circ}$ for the classification. The final Landsat 8 image classification includes water, bare soil/sand dunes and vegetated areas. The classification was repeated for Landsat images corresponding to the end of the rainy season and the end of the dry season to observe the respective distribution of water and vegetation covers in these two climatic end-members.

\subsection{Publication of Results on a Webmap for Dissemination and Evaluation}

Project results of an area necessarily pass through a cartographic representation. In recent years, dynamic and web mapping have constantly grown as a direct consequence of the development of 
digital technologies and the wide diffusion of the Internet. This has created new methods of map production, instead of pure desktop GIS, making them more accessible, both technologically and economically. This new cartography has become one of the best tools for disseminating information and making it accessible to all [21]. Dynamic webmaps allow for a definition of the different dimensions of the project, involving wide, intermediate and detail scales, public and private corporate players, and different kinds of actions [22]. In this kind of project, one of the main goals is to make data accessible and easy to use by the general public and for NGO (non-governmental organizations) staff. Hence, it is very important to angle towards an application usable by the general public but, at the same time, preserve scientific rigour.

For these reasons, the main results of this project were uploaded on a webmap platform, accessible at the link www.geositlab.unito.it/rimrap, to facilitate their easy access by the local authorities and technical operators. The platform was obtained using the open-source QGIS plugin "QGIS2web" to create an html page that contained the cartographical data in an interactive and user-friendly map. This final product is accessible online but was also delivered to the local actors in an offline version in order to facilitate accessibility, even in the absence of a good internet connection.

\section{Results}

\subsection{Onsite Survey}

The map in Figure 2 shows the 31 municipalities' chief towns, the administrative boundaries of the municipalities, the 265 agro-pastoral communities and the water wells surveyed in this research and in previous studies $[8,11]$.

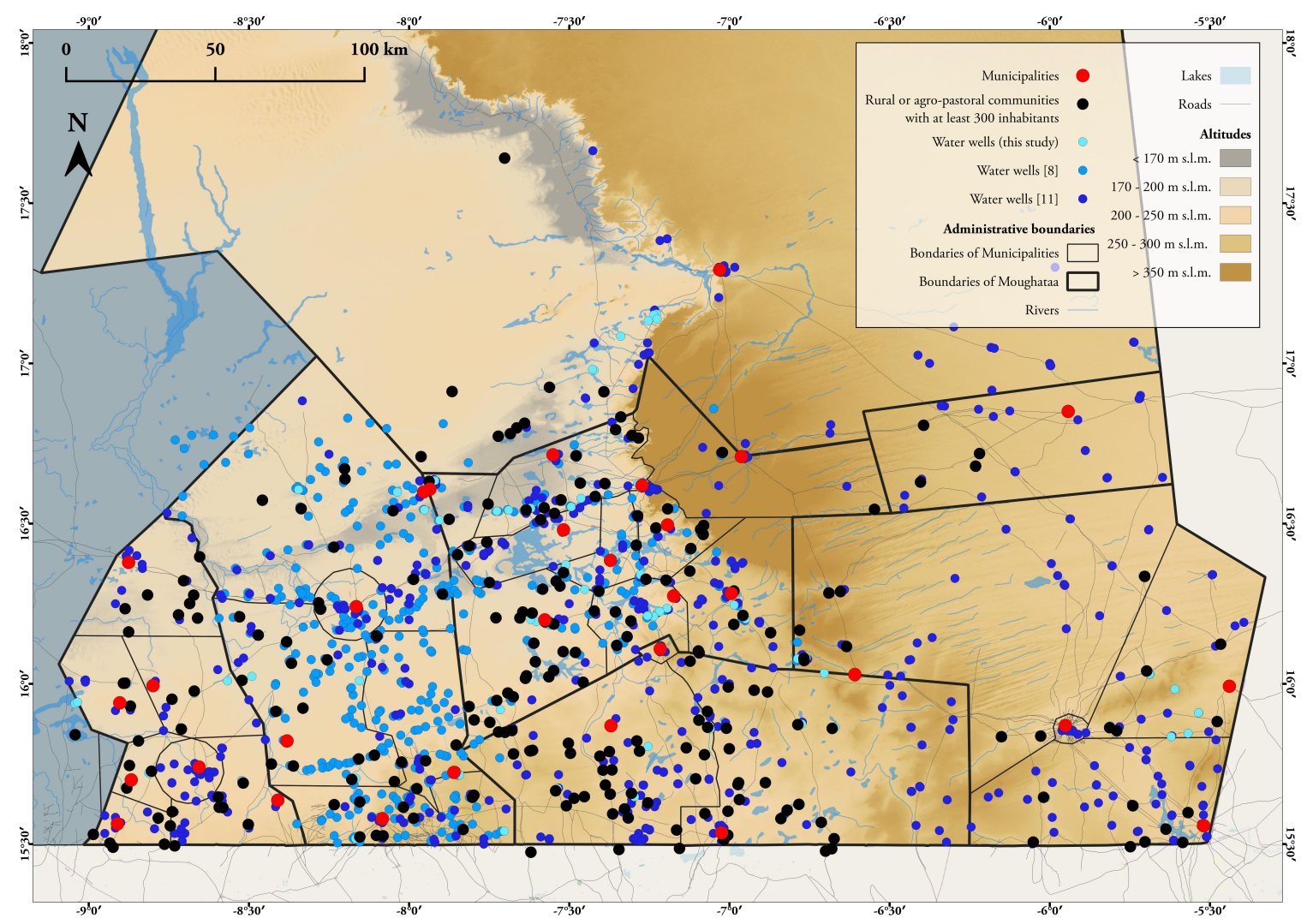

Figure 2. Administrative maps of the Hodh el Chargui, with the surveyed municipalities, communities and water wells. 


\subsubsection{Demography and General Information}

The survey in the municipalities of Hodh el Chargui recorded 469,477 people, with $47 \%$ males and $53 \%$ females. The resulting repartition of this population on the 31 municipalities of the region is shown in Figure 3a, while Figure 3b shows the human density of each of the municipalities.

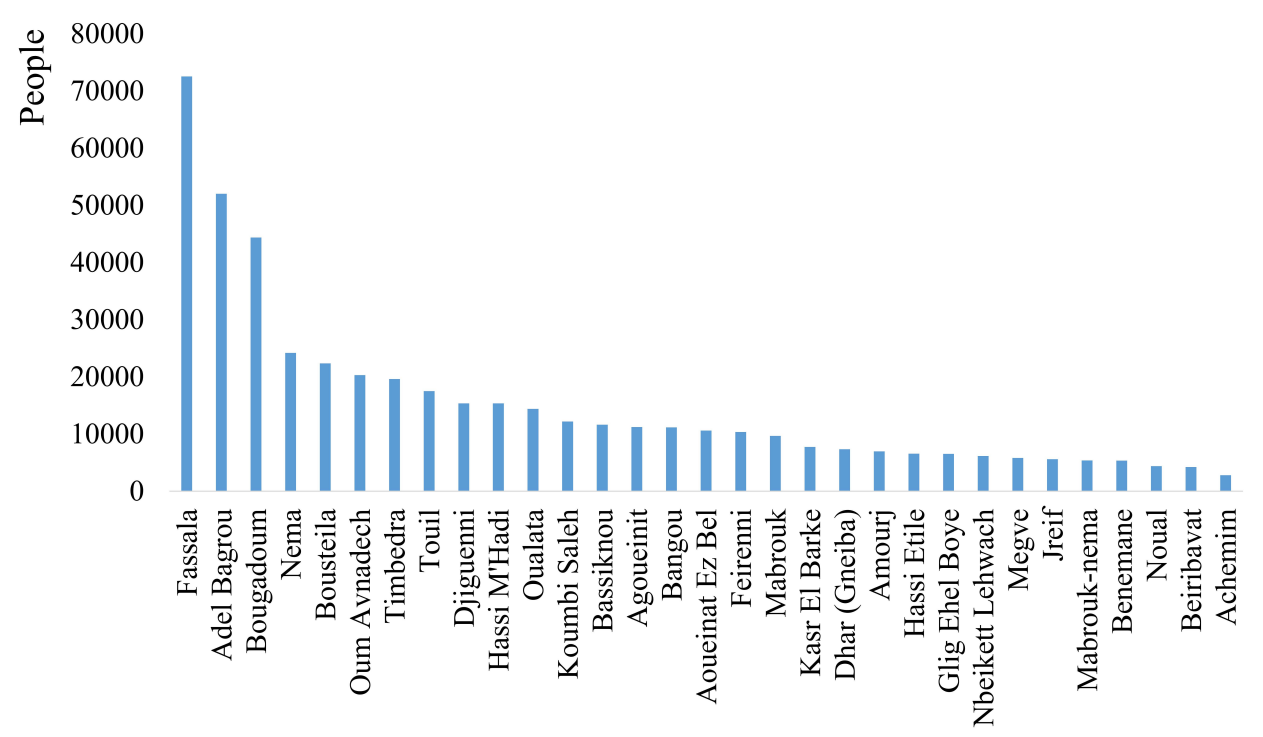

(a)

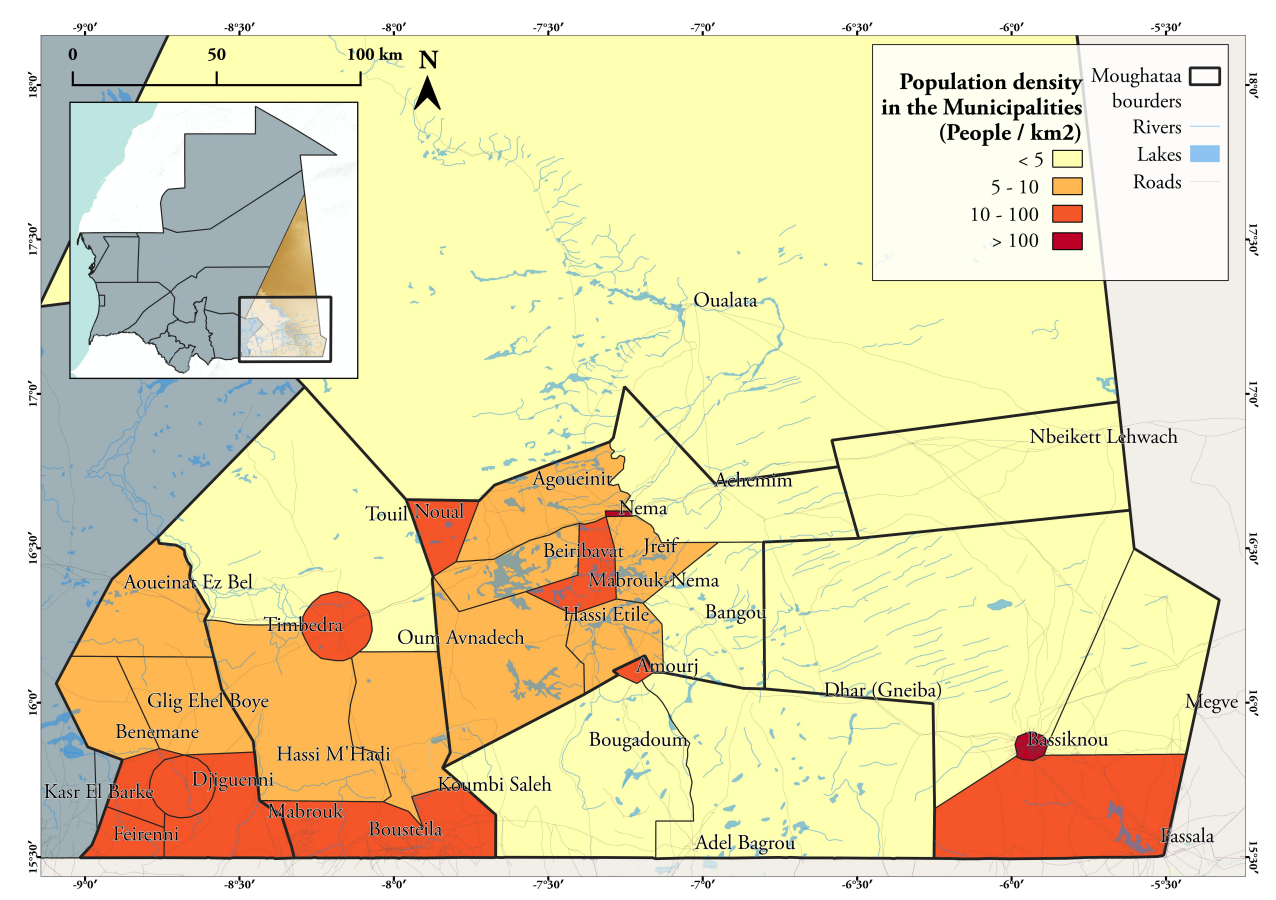

(b)

Figure 3. (a) Number of people living in each of the municipalities; (b) population density in the 31 municipalities of the Hodh el Chargui region.

The map in Figure 4 shows the percentages of literate people (i.e., people who have received basic school education) for men and women, respectively. The overall literate population is around $25 \%$, with values around $30 \%$ for the male population and around $20 \%$ for the female population. The highest percentages of literate people ( $42 \%$ and $38 \%$ ) may be found in the Moughataas of Nema and Djiguenni, respectively, in the municipalities of Mabrouk and Djiguenni itself. 


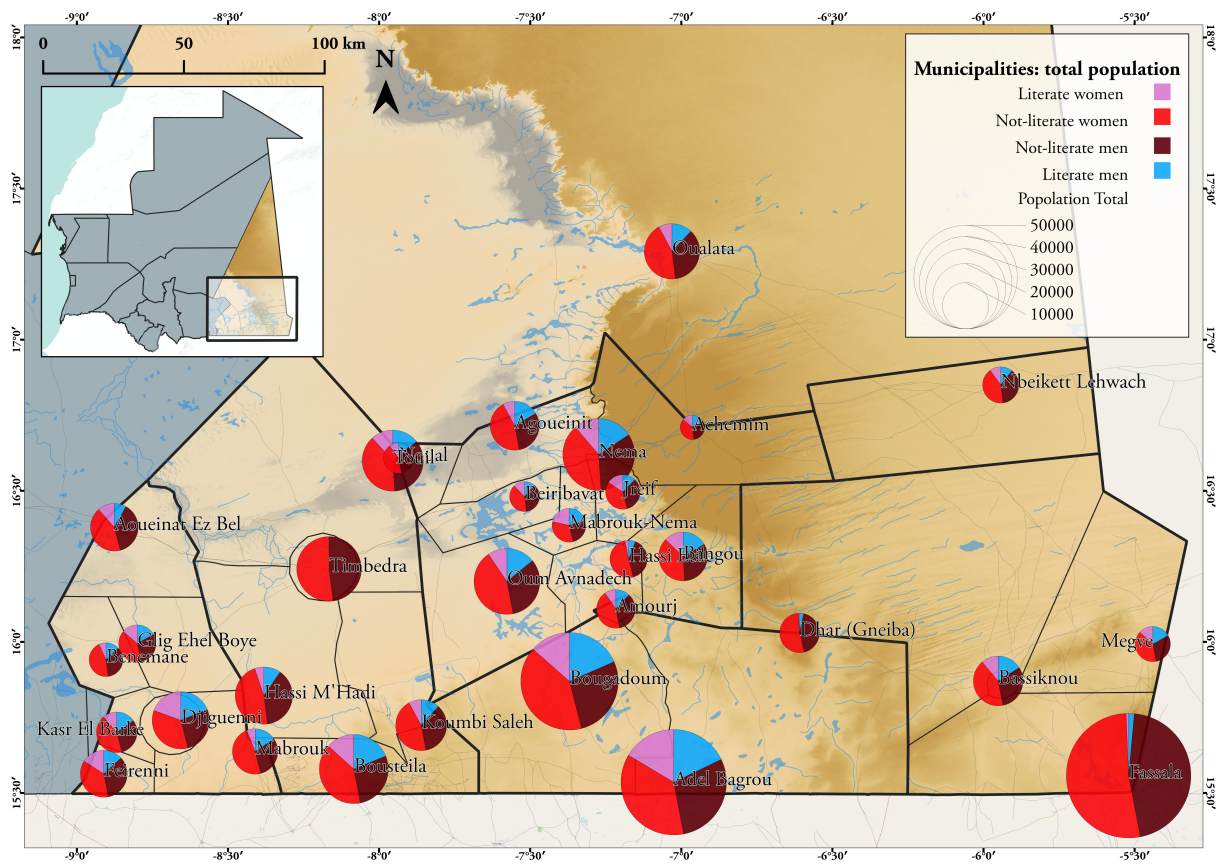

Figure 4. Percentage of males and females and literate and not-literate people in the 31 municipalities of the region.

The features of the habitations in the agro-pastoral communities were surveyed, distinguishing between "En banco" habitations, hard dwellings, semihard dwellings, stone buildings, tents and sheds. The map in Figure 5 shows, for each community, the principal type. As can be seen in the pie chart, the majority of the communities are characterized by habitations "En banco", followed by sheds and, in a lower proportion, stone buildings. A small percentage of the communities see the prevalence of hard buildings, while none of them described tents or semihard buildings as the principal type of habitation.

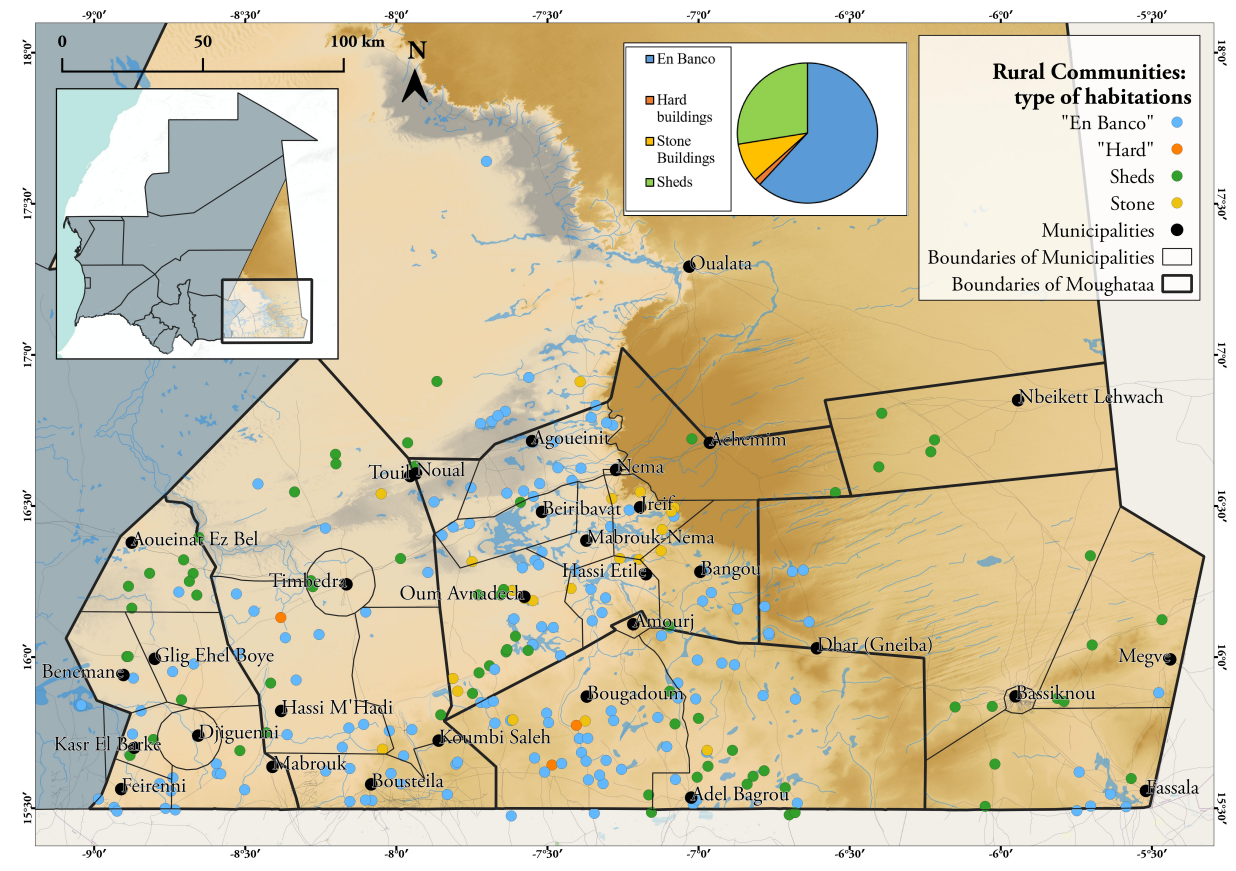

Figure 5. Principal type of habitation in all the rural communities with at least 300 inhabitants of the region. 
The survey also enquired about the availability of toilets, attesting that they are available in $60 \%$ of the communities.

\subsubsection{Infrastructure}

The availability of infrastructure in the rural communities is an important parameter, well-representing the resilience of a society, since a capillary distribution of services in the territory means easier access for all the inhabitants of the region. The surveyed infrastructures involve water management, energy, health, education, transportation and telecommunications.

In the Hodh el Chargui, the main water resource is groundwater, since surface water usually shows an ephemeral character. The most important infrastructure for water management is, therefore, the water wells for access to drinking water for both human and animal use. In the survey, three different types of water wells were considered:

- well: hand-excavated wells and, therefore, generally shallow, with manual systems for the water extraction;

- drainage well: large diameter wells (1-2 m), shallow, hand-dug, where the groundwater flows by gravity;

- borehole: small-diameter hole advanced below the ground surface by various drilling rigs, mostly equipped with a pump.

The total number of these types of wells and their activity status are reported in Figure 6.

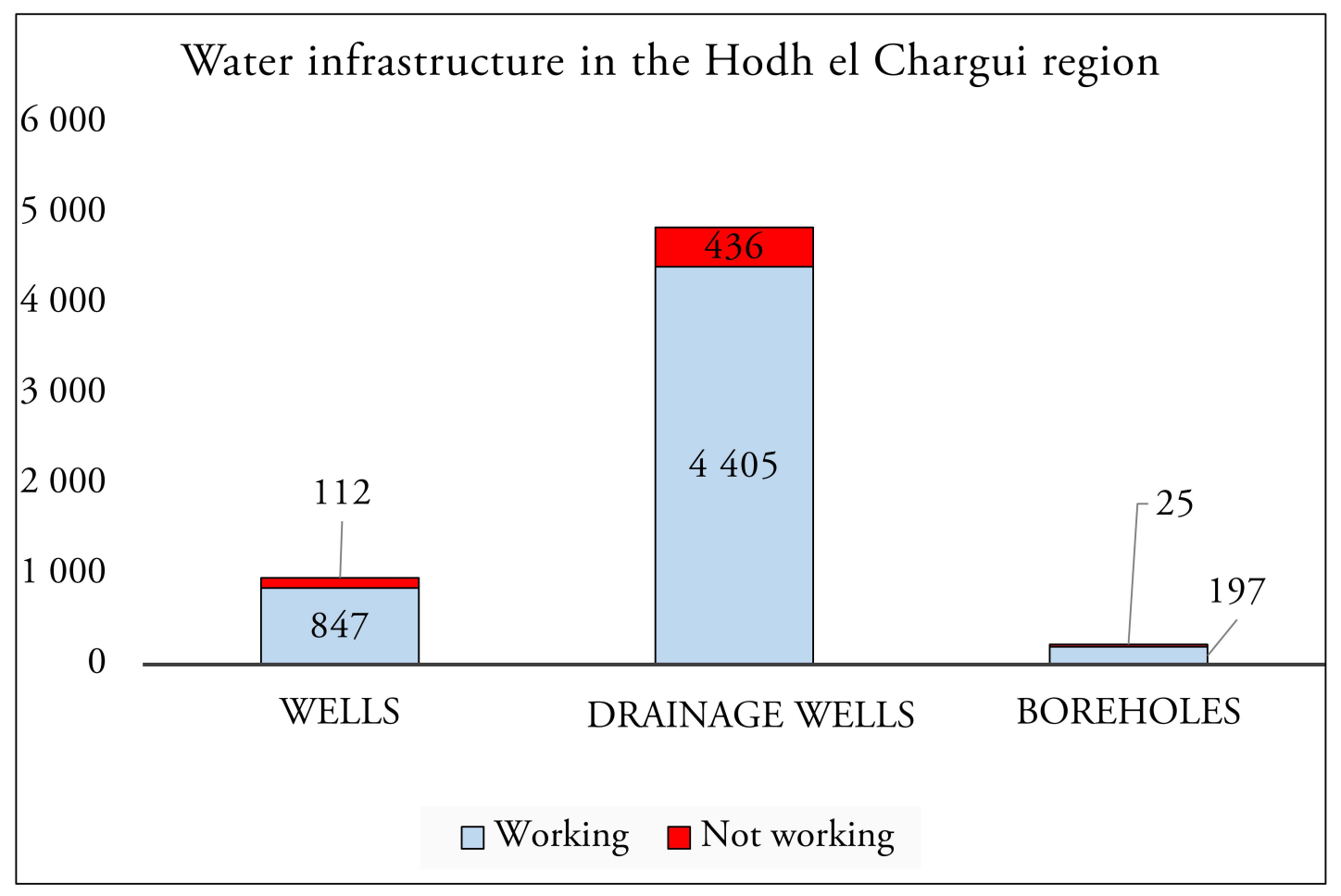

Figure 6. Total number of wells, cistern wells and boreholes in the region and their activity status.

In addition, the survey collected data about springs (i.e., places where water emerges naturally from the rock or soil).

As shown in the map in Figure 7a, many of the communities have more than one water well in the neighbouring area, with a mean number of 17 . However, the absence of controlled and scientific-based management and organization of the number of wells often affects their activity status. 


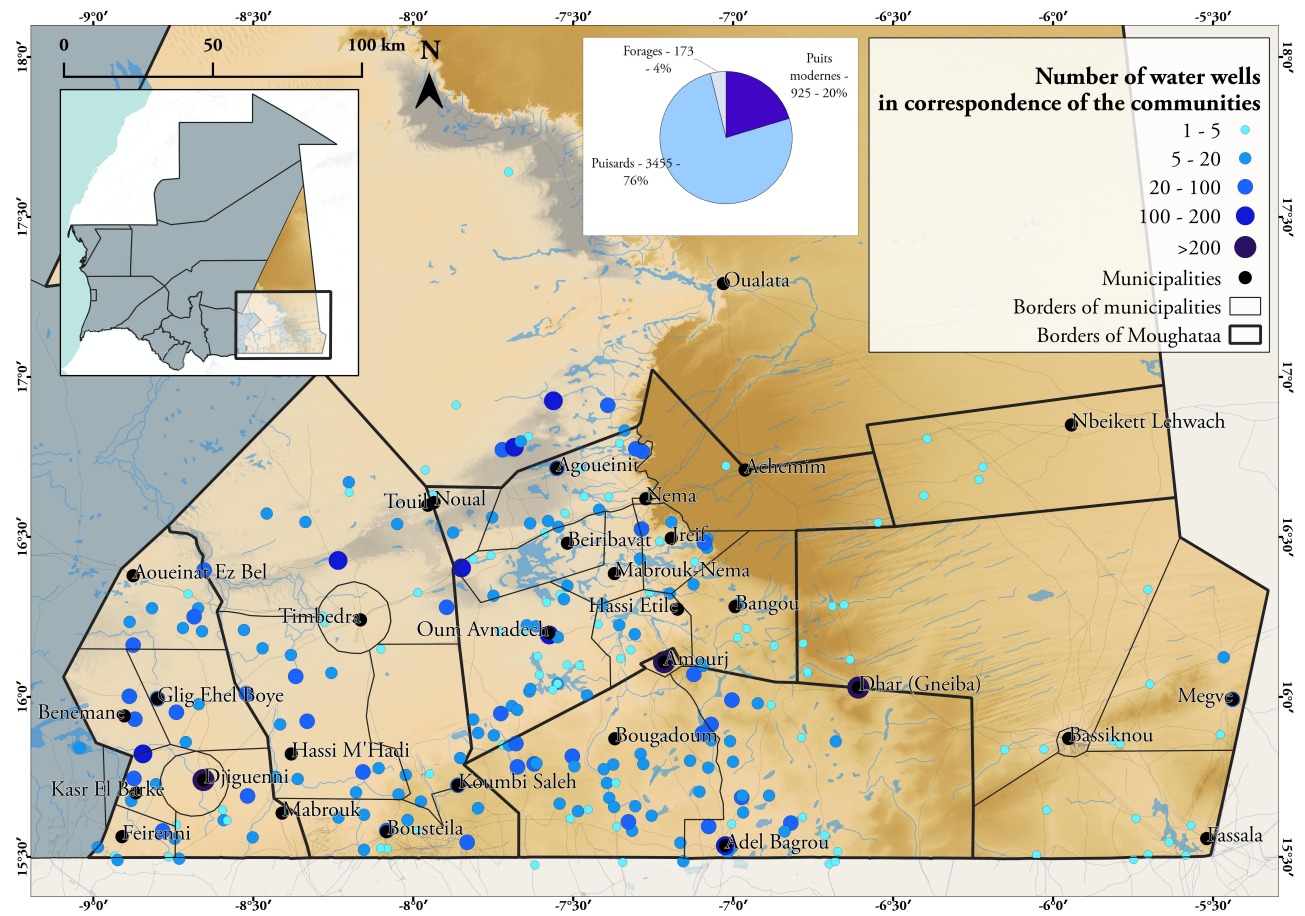

(a)

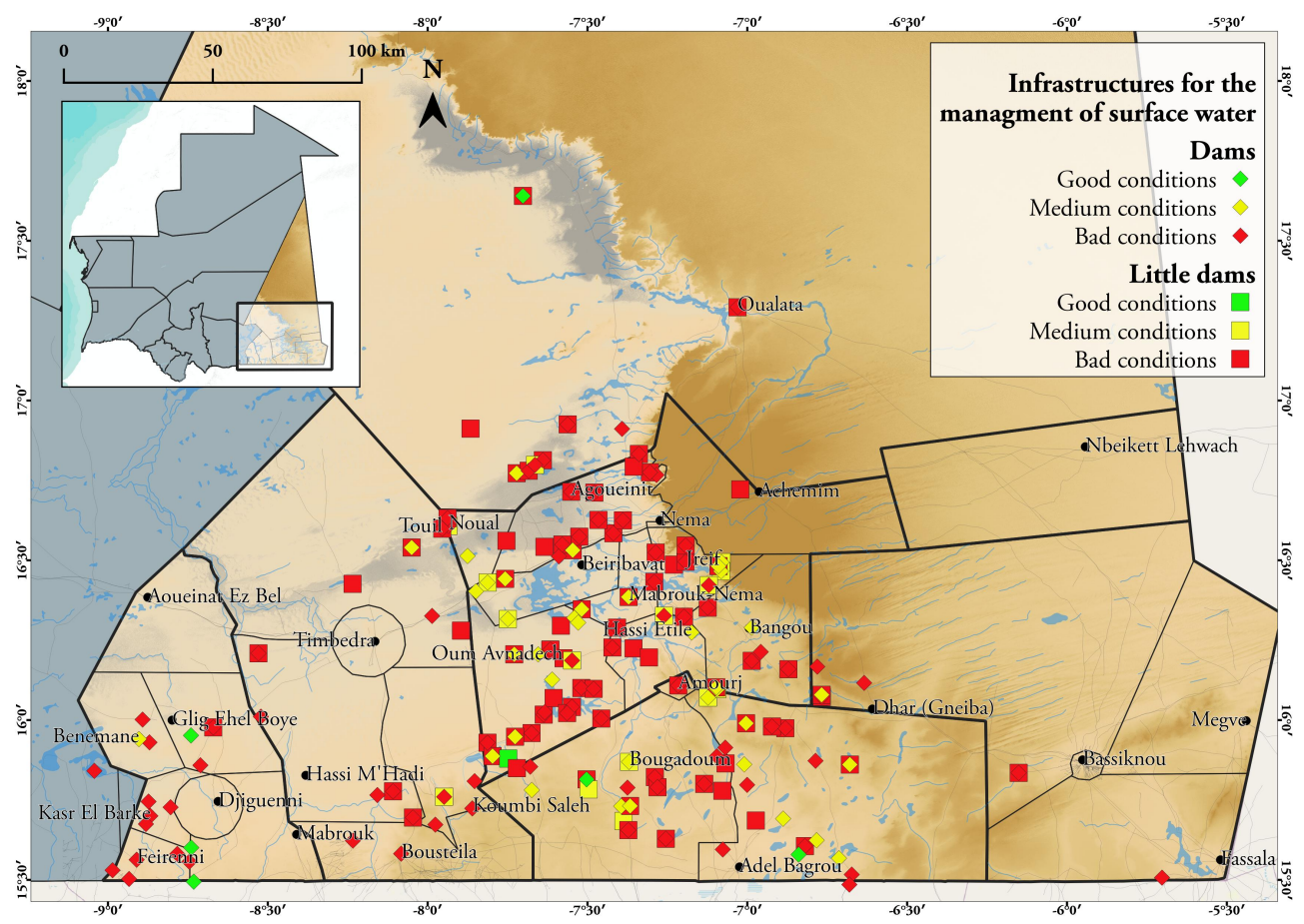

(b)

Figure 7. (a) Maps of infrastructure for the access to groundwater; (b) maps of infrastructure for the management of surface water.

Despite the predominant role covered by the groundwater, a specific relevance is connected to the infrastructure for the management of surface water (e.g., dams, barriers) for agriculture purposes (e.g., irrigation). The distribution and the conditions of this kind of infrastructure are reported in Figure $7 \mathrm{~b}$. As shown in the map, despite a large number of structures, the conditions are often bad, affecting the real state of operation. 
The infrastructure for energy mainly includes photovoltaic systems. Other energy sources were surveyed (i.e., wind systems and generators), but their presence was registered only in the municipalities of Adel Bagrou and Aoueinat Ez Bel, respectively. The photovoltaic systems, on the other hand, are present in $48 \%$ of the municipalities, while only $35 \%$ have a connection to the electricity network. The photovoltaic systems are also well developed in the rural communities, especially in the region of Nema (Figure 8).

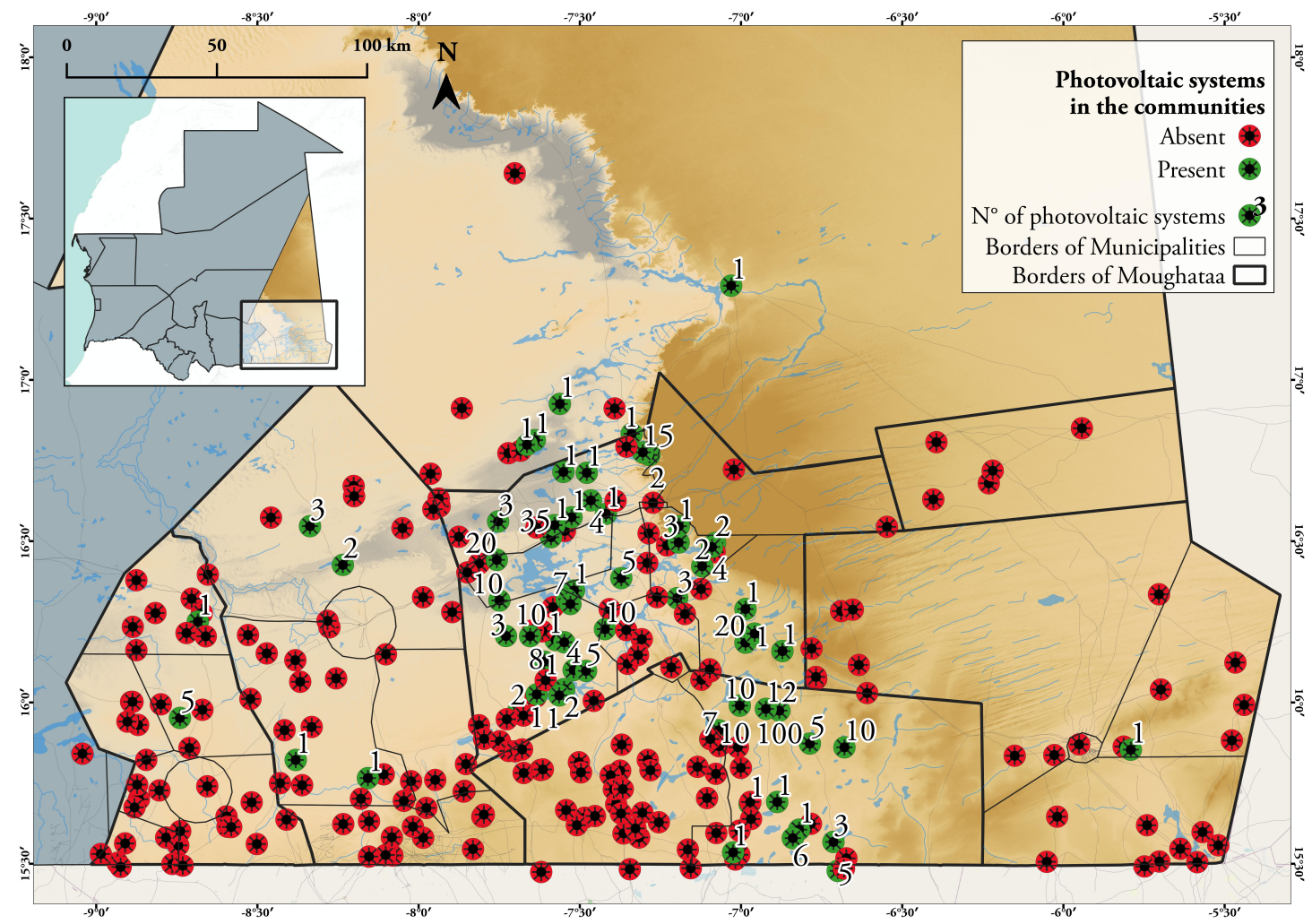

Figure 8. Availability of photovoltaic systems in the communities.

The infrastructure dedicated to healthcare (i.e., hospitals, dispensaries and health units) is present in $43 \%$ of the surveyed communities, following the distribution reported in Figure 9a. Among the remaining $57 \%$ (i.e., 151 communities), 96 communities declared the availability of a means of transport to the nearest hospital in case of emergencies (i.e., handcart, car, or on the back of an animal), following the chart in Figure 9b.

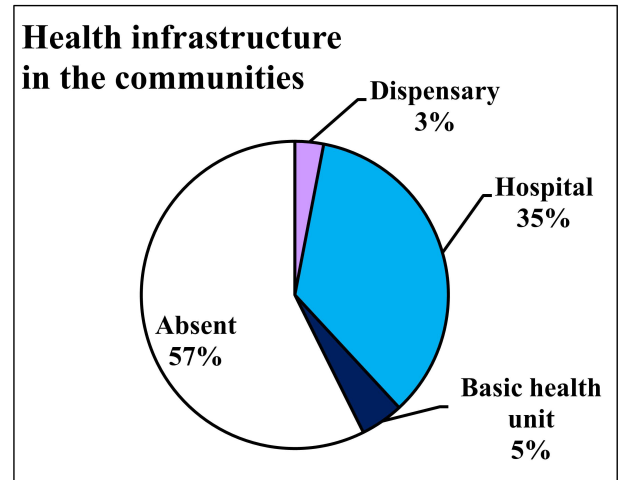

(a)

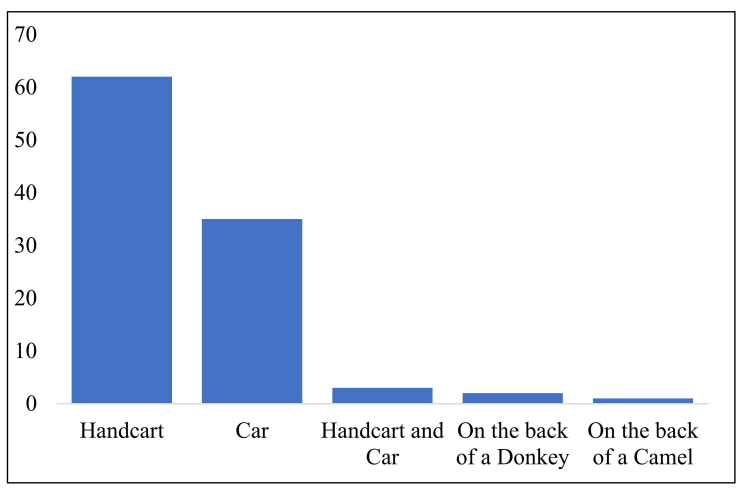

(b)

Figure 9. (a) Percentages of communities with dispensaries, hospitals and basic health units; (b) means of transport available in the communities without infrastructure for healthcare onsite. 
The education infrastructure (i.e., schools) represents one of the most important elements for the improvement of the local communities. The percentage of communities provided with a school is high (i.e., $94 \%$ ). However, the conditions of the school buildings are bad in $48 \%$ of the cases (Figure 10).

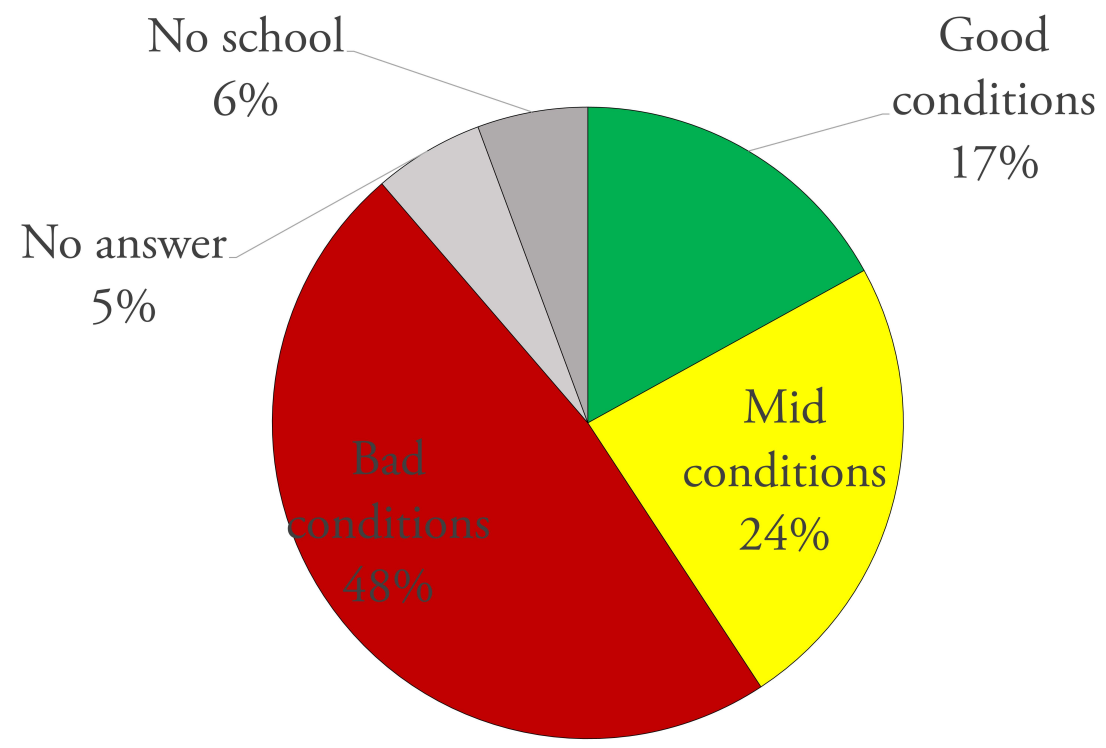

Figure 10. Conditions of the dwellings of the schools in the communities.

Regarding transport infrastructure, the presence of asphalt roads was attested in only 23 of the 265 surveyed rural communities (Figure 11). The remaining communities are usually crossed by a natural road. These kinds of roads are often interrupted by the effect of the rainfall, for mean time periods that range between 1 day and 6 months, as reported on the map in Figure 11.

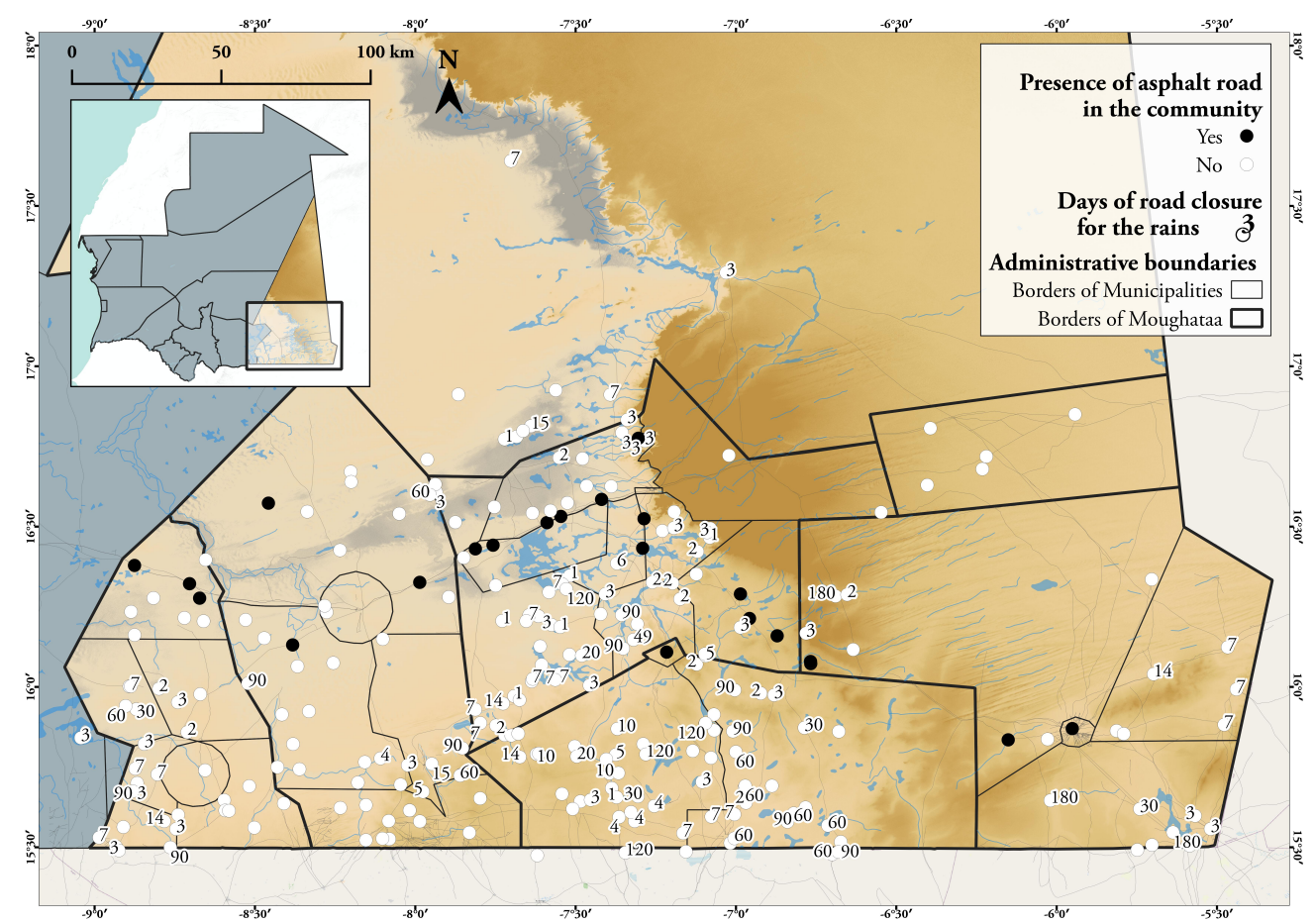

Figure 11. Map of availability of asphalt roads in the communities. For the communities without the presence of asphalt roads, the mean number of days of road closure caused by seasonal rainfall is reported. 
Eventually, a good distribution of communication infrastructure was surveyed on the territory, at least in terms of mobile phone networks, which are present in $84.5 \%$ of the communities. Internet network, radio and television are less diffused, with percentages of $17.0 \%, 37.4 \%$ and $18.9 \%$, respectively.

\subsubsection{Principal Economic Activities}

As shown in Figure 12, the first economic activity in the majority of the communities is pastoralism, followed by agriculture. Other types of activities, such as commerce and artisanship, are, however, present, but to a lower extent. The mean percentages of men and women performing the different professions are reported in Table 1.

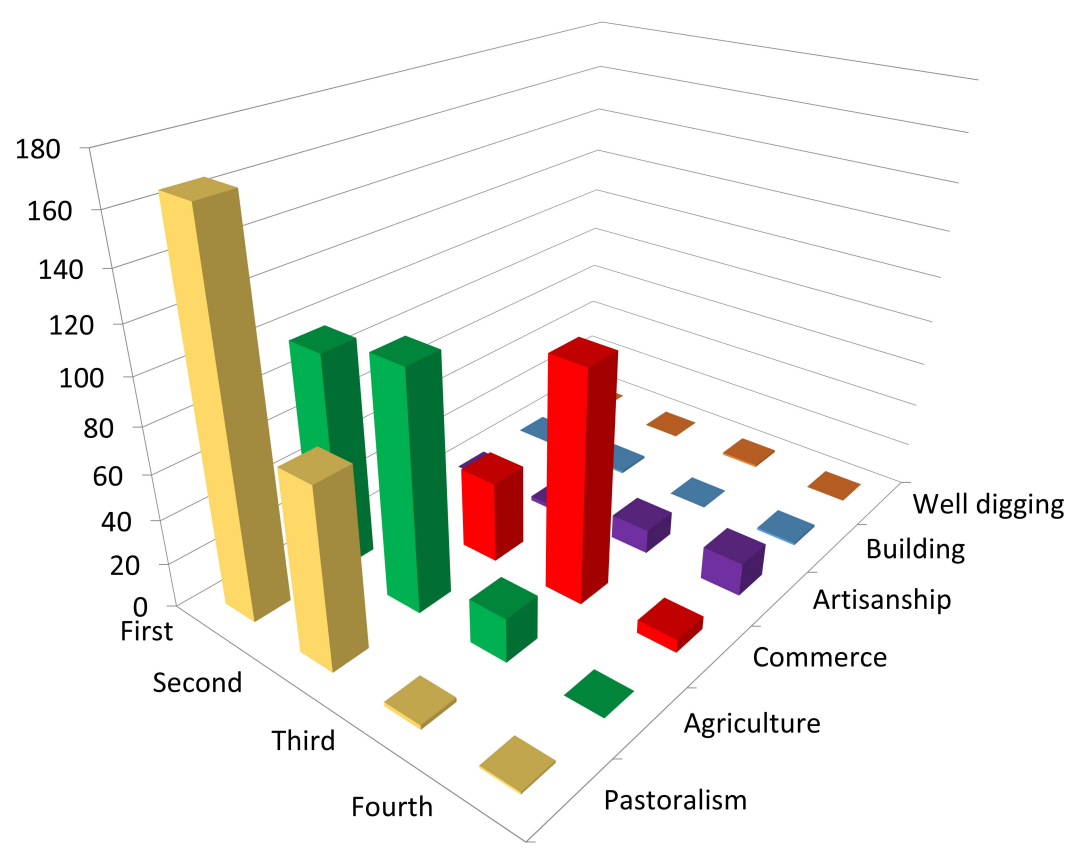

Figure 12. Number of communities that consider each economic activity, respectively, the first, the second, the third, or the fourth as important for their local economy.

Table 1. Repartition of the principal professions between men and women.

\begin{tabular}{ccc}
\hline Profession & Men (\%) & Women (\%) \\
\hline Baker & 96 & 4 \\
Butcher & 55 & 45 \\
Trader & 61 & 39 \\
Carpenter & 100 & 0 \\
Tailor & 82 & 18 \\
Weaver & 8 & 92 \\
Ironworker & 100 & 0 \\
Tanner & 0 & 100 \\
Builder & 100 & 0 \\
Digger & 100 & 0 \\
\hline
\end{tabular}

Hence, the main economic activity of the region is pastoralism, a sector that is well established and largely produces for export to other regions of the country and abroad. The activity is, however, strongly affected by seasonality. As shown in Figure 13a, indeed, the distance of the pastures from the communities is one order of magnitude higher during the dry season. In these periods, most of the shepherds migrate to the southern pastures, and only a small part of the livestock remains in the communities for requirements of milk, cheese, and meat (Figure 13b). 


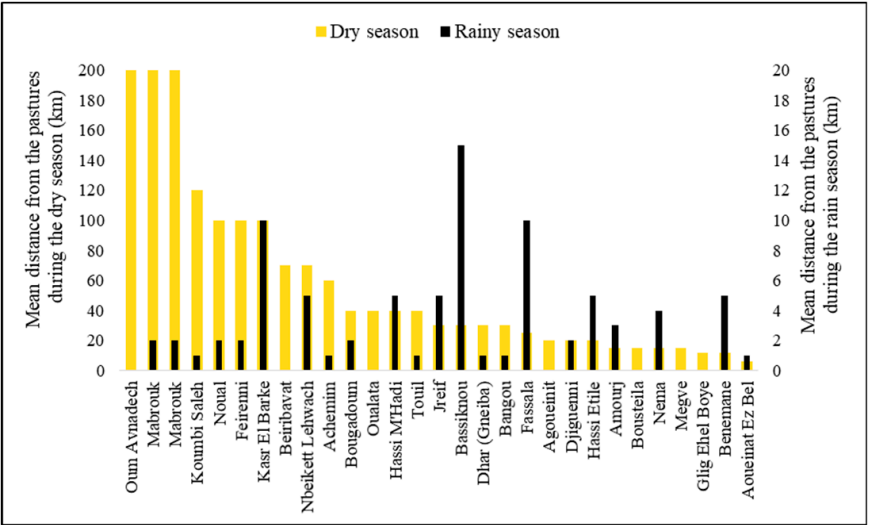

(a)

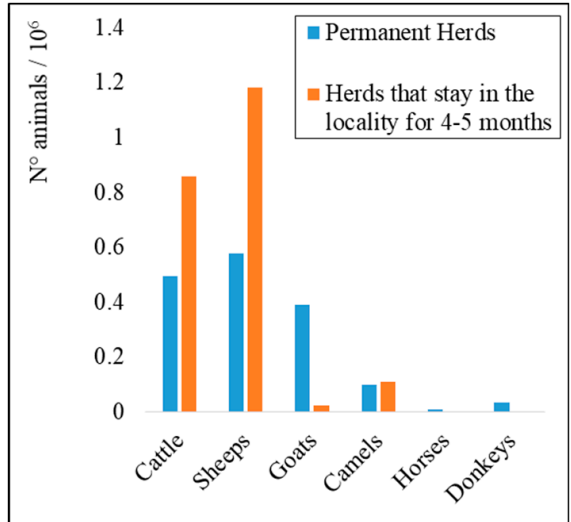

(b)

Figure 13. (a) Mean distance of the communities from the pastures during the dry and rainy seasons.

(b) Features of the herds in the communities.

Agriculture, on the other hand, is strongly affected by the dry climate and the want of surface water resources. Hence, it is less developed, not being able to supply the needs of the region entirely. Recently, however, some experiences of local agricultural production have started. They mainly involve the production of vegetable crops, especially short cycle plants, which give their product in a few weeks and are therefore less sensitive to the possibility of lack of water.

In other frameworks with similar environmental conditions (e.g., [23]), the success of agricultural activities was mainly related to the introduction of innovative technologies, for instance, the use of specific seeds for semiarid areas or the application of innovative irrigation techniques (e.g., "drip solar" irrigation systems). Similar techniques may also allow the success of agricultural production in the Hodh el Chargui region, despite the arid conditions.

\subsubsection{Natural Resources}

The availability of natural resources (i.e., surface water, groundwater and vegetation) mainly depends on seasonal precipitations. The rainy season starts between July and August and ends between September and October, as attested by the survey in the communities (Figure 14).

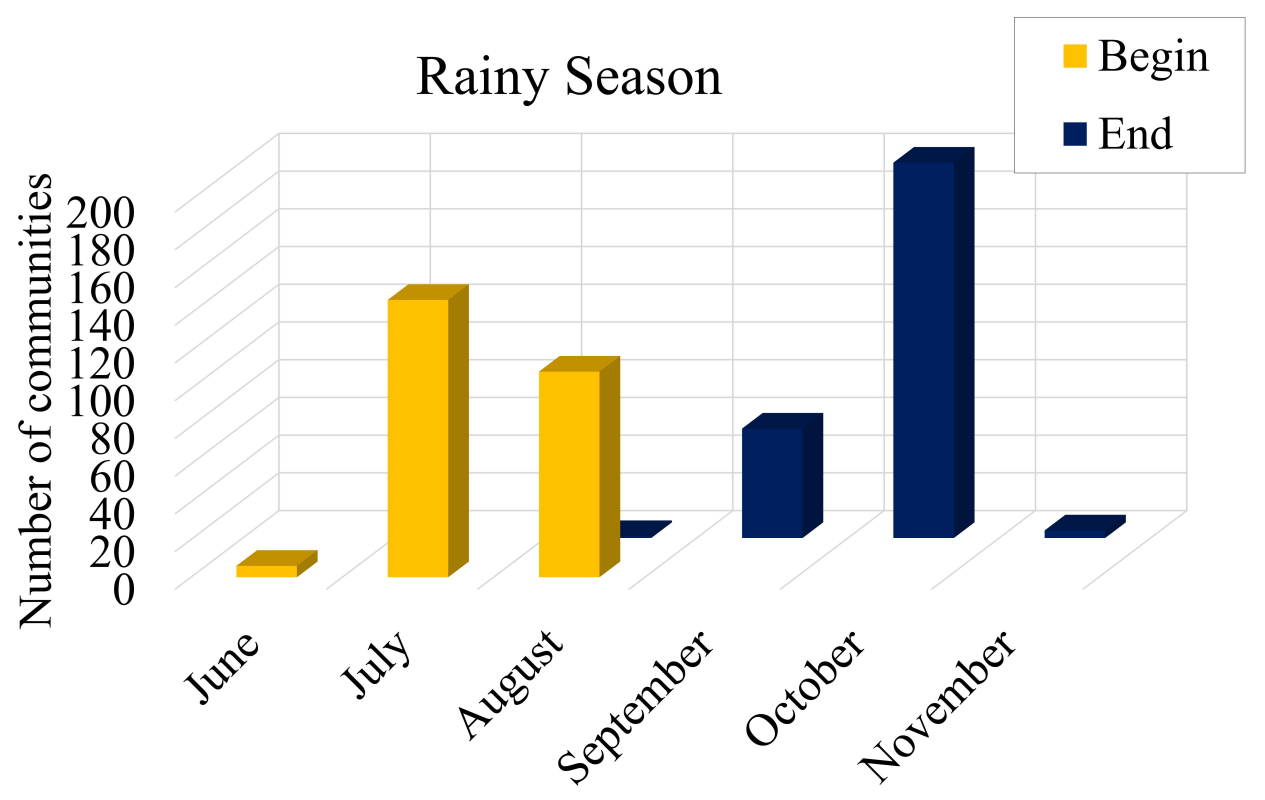

Figure 14. Answers of the communities about the beginning and end of the rainy season. 
The survey also proposes an evaluation of the vegetal resources in the area: each community is invited to identify the principal type of natural or seminatural vegetation present in the neighbouring area (Figure 15). As can be seen, the majority of the communities (51\%) identify the presence of shrub savannah, with low shrubs and grazing grass. These kinds of spaces are good for used as animal pastures during the rainy season. After long periods of drought, however, this low vegetation usually disappears, and in the late dry season, these pastures are usually completely dry.

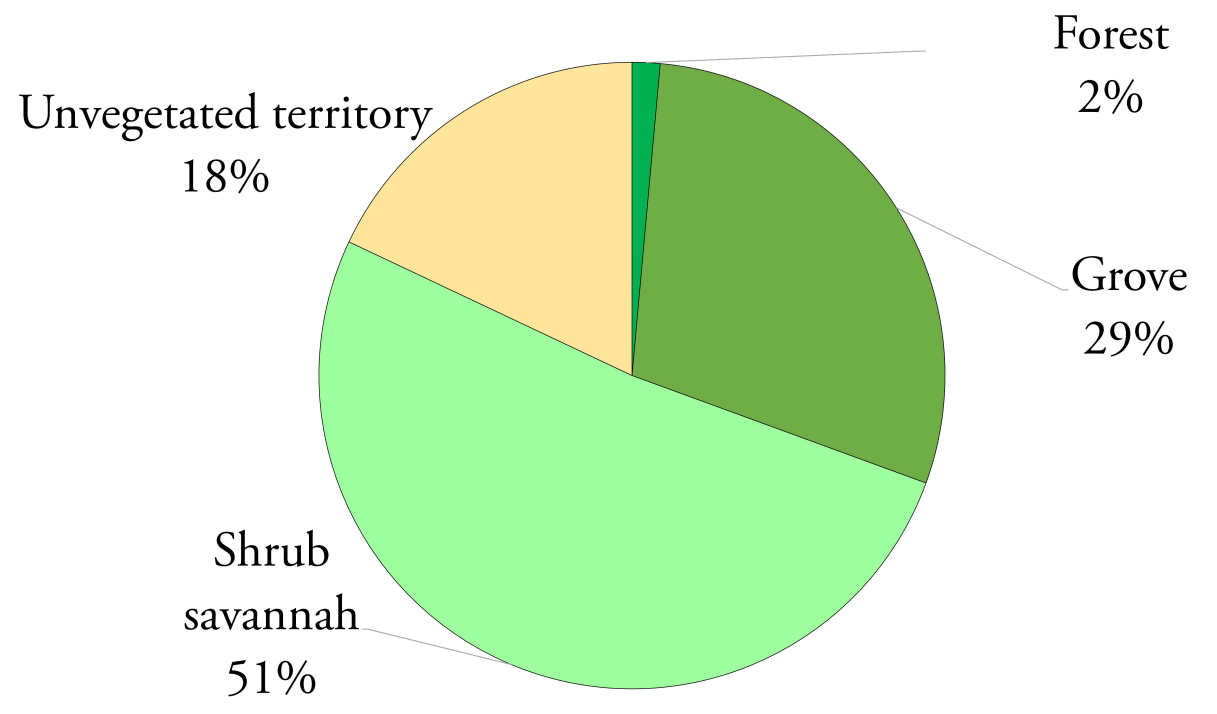

Figure 15. Types of seminatural vegetation present in correspondence of the communities.

A high percentage of the communities (29\%) attested the presence of a grove, similar to the shrub savannah, but with the presence of a few tall trees. Additionally, in these conditions, the long dry seasons usually dry the grass used as pastures during the rains. Only $2 \%$ of the communities describe the presence of "forest", usually in correspondence to a river of a water stream that, during the rainy season, assures a large availability of water and a more abundant growth of vegetation, with tall trees.

The absence of any kind of vegetation, even during the rainy season, or the presence of sand dunes is attested in $18 \%$ of communities.

The availability of water resources mainly depends on the groundwater that should also guarantee the hydric supply during the long months of the dry season.

Nevertheless, for the majority of the considered wells, the survey identified the existence of a season when wells run dry. As can be seen in Figure 16, this period is between April and May/June, i.e., in correspondence with the end of the long dry season. This phenomenon may be due to several reasons, e.g., excessive water extraction, long drought periods or the short distance between the wells.

The discharge of the pumps (reported for $22 \%$ of the wells) is mainly lower than $1 \mathrm{~m}^{3} / \mathrm{h}(23 \%)$ or in the range of 1 and $10(57 \%) \mathrm{m}^{3} / \mathrm{h}$. Values higher than $20 \mathrm{~m}^{3} / \mathrm{h}$ are mainly related to boreholes or modern wells, emphasising the importance of modern infrastructure for water supply needs.

From a geographical point of view, clear differences in water depth can be recognised between the eastern and western parts of the region. In Figure 17, the depth of the static level for the surveyed wells is reported, highlighting in the eastern plateau a majority of wells with depth values higher than $40 \mathrm{~m}$ (i.e., less favourable conditions for the extraction of groundwater). In the western sector, on the other hand, values are generally lower than $30 \mathrm{~m}$, and depth values are widely inhomogeneous.

This situation is coherent with the conceptual hydrogeological model proposed by [8], which includes three main hydrogeological units: the Upper Neoproterozoic hydrogeological unit, within the marine sediments that make up the ancient basement; the Mesozoic hydrogeological unit, within the Jurassic dolerites and Cretaceous sandstones that characterise the Dhar of Nema; the Quaternary hydrogeological unit, mainly consisting of aeolian sandy deposits and ancient and recent alluvial deposits, emerging in the wadis. 


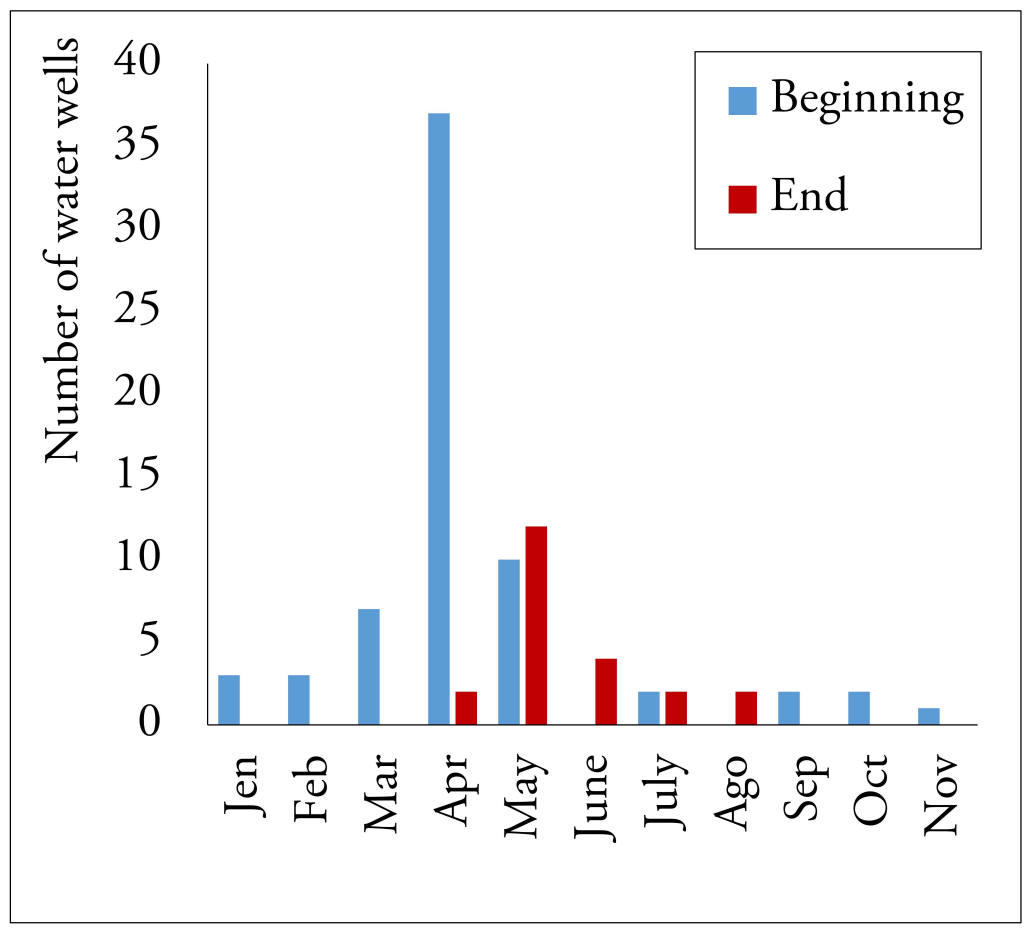

Figure 16. Beginning and end of the season when wells run dry.

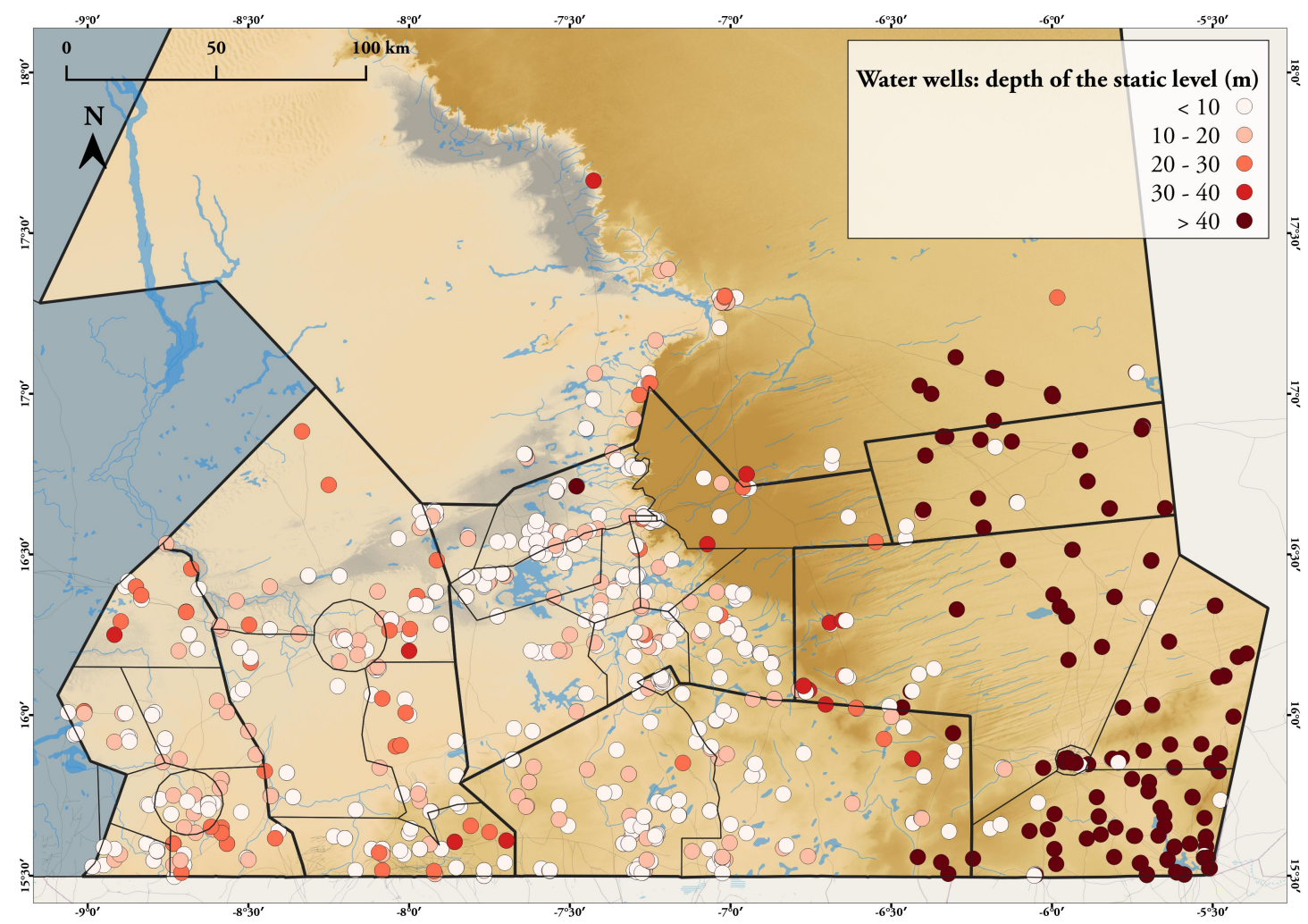

Figure 17. Map of the depth of the static level in the water wells surveyed in this study and in [11].

Hence, the higher depths registered in the eastern area should correspond to aquifers in correspondence to the Mesozoic sediments of the Dhar plateau, while the shallow features and the inhomogeneous distribution of the measurements in the western area confirm the existence of multiple aquifers within the recent aeolian and alluvial deposits, with higher geological variability. 
In addition to the quantitative features of groundwater resources, the survey also provided information about the water qualitative parameters, collecting both objective (e.g., electrical conductivity) and subjective (e.g., taste, smell, colour) ones.

The electrical conductivity provides important information about the salinity and, consequently, the drinkability of groundwater. For human use, no WHO health-based guideline value was established; however, a value of $2500 \mu \mathrm{S} \mathrm{cm}^{-1}$ at $20^{\circ} \mathrm{C}$ is indicated in a WHO directive [24], reflecting what is both achievable and acceptable to consumers.

For animals, generally, higher salt content is accepted, with maximum values between 5000 and $10,000 \mathrm{microS} / \mathrm{cm}$, depending on the type of animal [25]. Even though the majority of the surveyed wells returned values lower than $2500 \mathrm{microS} / \mathrm{cm}$, the maximum value registered in the area is very high, up to 15,000 microS/cm (i.e., not acceptable values, not even for animals). As shown in Figure 18, these anomalously high values are randomly present in the whole region. The absence of a clear distribution is probably due to the low continuity of the water bodies and the different depths of the wells.

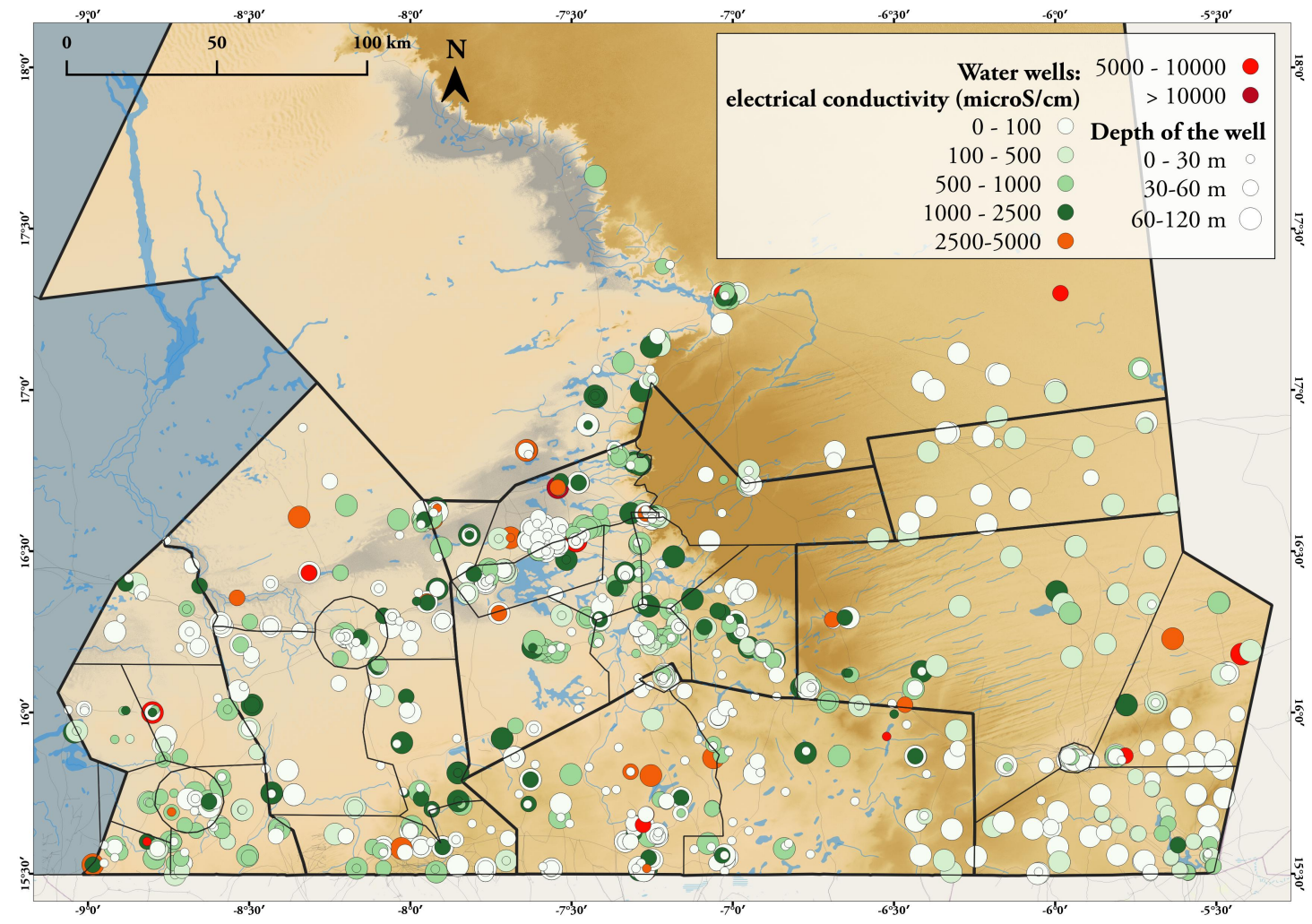

Figure 18. Map of the conductivity and the total depth of the wells surveyed in this study and in [11].

The qualitative evaluations of the water taste return values are in line with the measures of electrical conductivity, again highlighting the existence of the problem of high salinity water, as reported in Table 2.

Table 2. Qualitative classification of water salinity in wells, based on the subjective evaluation of taste.

\begin{tabular}{cc}
\hline Taste & Number of Water Wells \\
\hline Very salty & 1 \\
Salty & 2 \\
Slightly salty & 39 \\
Heavy & 12 \\
Sweet & 44 \\
\hline
\end{tabular}




\subsubsection{Influence of Climatic Change}

The rainfall and meteorological characteristics of the two seasons of the year influence the hydrological risks. The survey on the communities investigated how these characteristics have changed in the last 10 years as a consequence of worldwide climate change. The results, summarised in Tables 3 and 4, testify to a general increase in temperatures. In addition, the rainy season was described, in the majority of the cases, as shorter and with less intense and less frequent rainfall events. As a consequence, floods (and related damages) were described as constant or in diminution, while an increase in drought events (and related damages) was registered in the majority of the communities.

Table 3. Answers of the communities in the survey about climate change during the last 20 years.

\begin{tabular}{cccc}
\hline & First Answer & Second Answer & Third Answer \\
\hline Rainy season & Shorter $(92 \%)$ & As usual $(3 \%)$ & Longer $(2 \%)$ \\
Dry season & Longer $(96 \%)$ & As usual $(3.5 \%)$ & Shorter $(0.5 \%)$ \\
Temperatures & Higher $(96 \%)$ & As usual $(4 \%)$ & Longer $(2 \%)$ \\
\hline
\end{tabular}

Table 4. Data about the increase or decrease of damage due to atmospheric events (wind storms, floods and droughts).

\begin{tabular}{cccc}
\hline & $\begin{array}{c}\text { More Frequent } \\
\text { (\% of Answers) }\end{array}$ & $\begin{array}{c}\text { As Usual } \\
\text { (\% of Answers) }\end{array}$ & $\begin{array}{c}\text { Less Frequent } \\
\text { (\% of Answers) }\end{array}$ \\
\hline Storms (strong wind) & 83 & 10 & 6 \\
Floods & 5 & 58 & 37 \\
Flood damages & 3 & 58 & 39 \\
Drought & 88 & 11 & 2 \\
Drought damages & 83 & 16 & 2 \\
\hline
\end{tabular}

According to the results of the survey in the 31 municipalities (Figure 19), the increasing drought events mostly caused damage to vegetation and pastures. Hence, a high impact is also registered for animals in need of pastures for their feeding. Agricultural products are in the third position, presumably because of the lower diffusion of this economic activity when compared to pastoralism. Water resources (i.e., mainly groundwater) having longer charging time and, therefore, a longer response to rain were less affected. Eventually, some records of people affected by drought events were reported, even though the survey does not investigate the specific reasons.

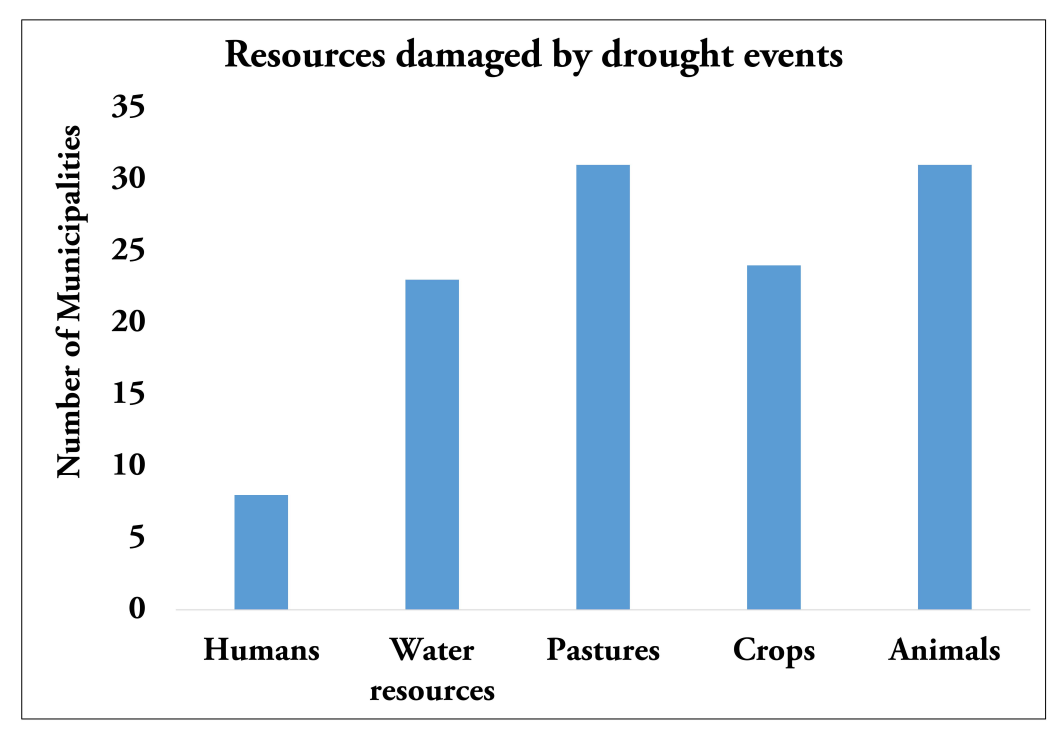

Figure 19. Most affected resources by the effects of drought. 


\subsection{Additional Analyses with EO Satellite Data}

\subsubsection{Watershed Basins}

The watershed basins extracted with the semiautomatic procedure for the area of Nema are shown in Figure 20. The river network was manually delineated following the Landsat8 images, using different false colour composites. The ephemeral rivers are complex and ramified in the northeastern part of the map, in correspondence with the Nema plateau. In this area, the presence of altitude variations favours the water flow along definite paths and increases the energy of water, enhancing its erosive power. In the flat area on the south-west, on the other hand, the water flows slowly, creating large swampy areas and lakes that, during the rainy period, are rich in water and vegetation.

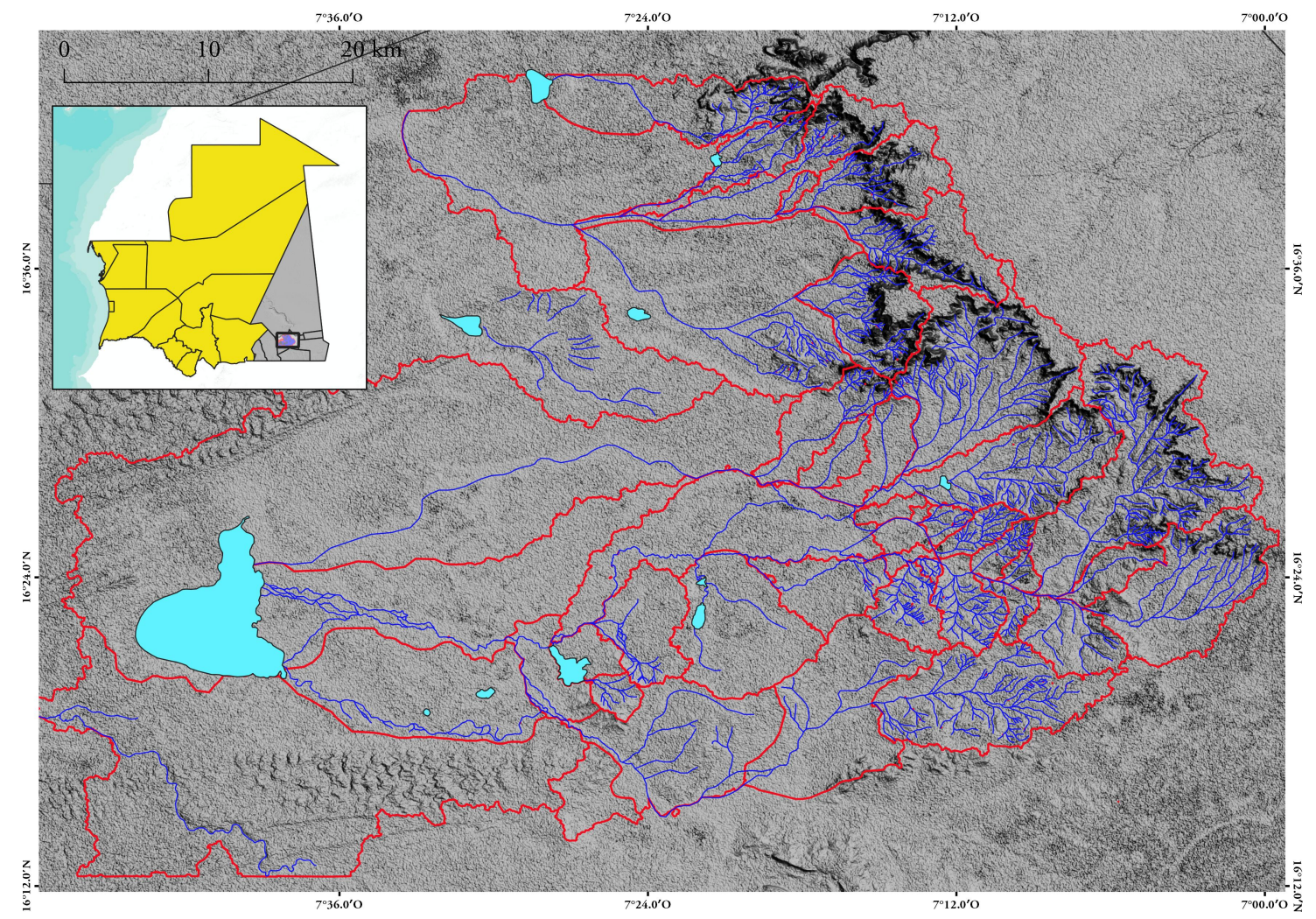

Figure 20. River network (in blue) and watershed basins (in red) defined for the area of Nema.

\subsubsection{Use of Land Cover Classification Maps}

Figure 21 shows the land cover classification for the area of the Hodh el Chargui. The map distinguishes between areas with vegetation, which may be used as pastures, and unvegetated areas, consisting of bare soil or sand dunes. Tables 5 and 6 report the size of the training samples (i.e., reference data) and the accuracy of the classification for the rainy season and the dry season, respectively. The drastically different results obtained for the rainy season (Figure 21a) and the dry season (Figure 21b) confirm the strong effect of seasonality on the availability of surface water and vegetation for the pastures. 


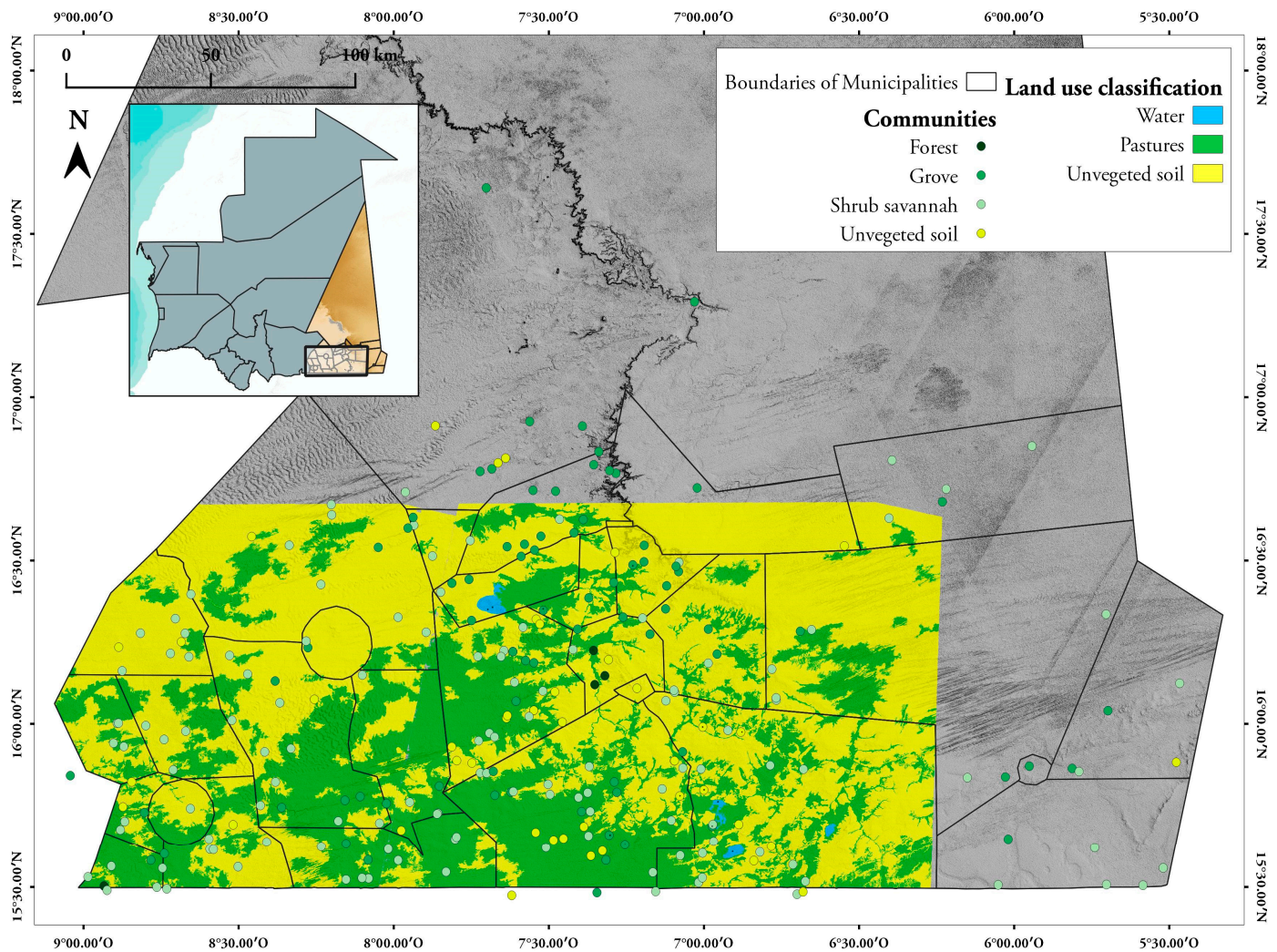

(a)

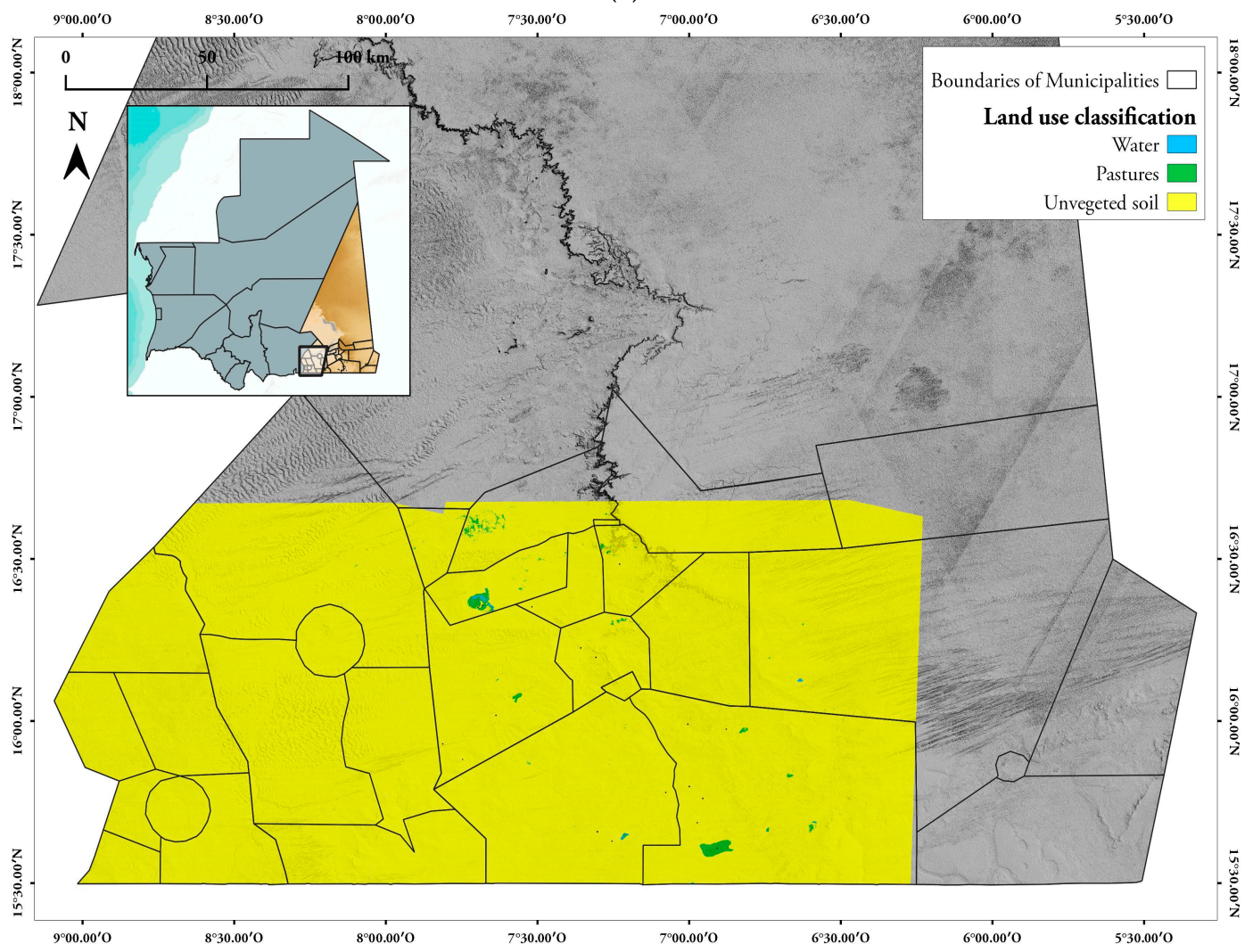

(b)

Figure 21. (a) Map of use of land classification at the end of the rainy season. (b) Map of use of land cover classification at the end of the dry season. 
Table 5. Error matrix of the classification procedure for the rainy season.

\begin{tabular}{cccccc}
\hline \multicolumn{5}{c}{ Reference Data } & \\
\hline Classified Data & Soil & Pastures & Water & Row Total & User's Accuracy \\
\hline Unclassified & 0 & 0 & 1112 & 1112 & \\
Soil & 2854 & 0 & 693 & 3547 & $80.46 \%$ \\
Pastures & 0 & 3511 & 418 & 3929 & $89.36 \%$ \\
Water & 0 & 0 & 1120 & 1120 & $100.00 \%$ \\
\hline Column Total & 2854 & 3511 & 3343 & 9708 & \\
Producer's Accuracy & $100.00 \%$ & $100.00 \%$ & $33.50 \%$ & Overall Accuracy $=77.10 \%$ \\
& & & & Overall Kappa Index $=0.68$ \\
\hline
\end{tabular}

Table 6. Error matrix of the classification procedure for the dry season.

\begin{tabular}{cccccc}
\hline \multicolumn{5}{c}{ Reference Data } & \\
\hline Classified Data & Soil & Pastures & Water & Row Total & User's Accuracy \\
\hline Unclassified & 0 & 0 & 0 & 0 & \\
Soil & 2854 & 338 & 180 & 3372 & $84.64 \%$ \\
Pastures & 0 & 3017 & 636 & 3653 & $82.59 \%$ \\
Water & 0 & 156 & 2527 & 2683 & $94.91 \%$ \\
\hline Column Total & 2854 & 3511 & 3343 & 9708 & \\
Producer's Accuracy & $100.00 \%$ & $85.93 \%$ & $75.59 \%$ & Overall Accuracy $=86.51 \%$ \\
& & & & Overall Kappa Index $=0.80$ \\
\hline
\end{tabular}

\subsection{Publication of Results on a Webmap for Dissemination and Evaluation}

The online web-GIS map is accessible at the link www.geositlab.unito.it/rimrap. The data reported on the maps include:

- information on the schools and hospitals available in the area;

- the surveyed wells, classified in terms of the state of activity, with an interactive form reporting the main information about the well features (depth, perennity, distance from the village, modality of water extraction) and the water features (temperature, electrical conductivity, taste);

- the location of the 265 surveyed rural communities, classified in terms of population, with an interactive form, including some basic information (e.g., name of the village, principal economic activity);

- a record of the improvement interventions performed in the framework of the RIMRAP project.

\section{Conclusions}

This study proposes an analysis of the vulnerability of the local communities in the Hodh el Chargui region (Mauritania) through the collection of heterogeneous data concerning environmental and socio-economic information. Data were collected with the combined use of an onsite survey, which involved the local population through a participatory approach, and techniques of Earth Observation.

The results provide a reliable framework of the local reality in terms of demographical, administrative and socio-economic features and availability of natural resources. The analysis includes an evaluation of the repartition between women and men, the percentage of the literate population, the infrastructure for the basic needs of the population and the principal economic activities, with specific attention to pastoralism and agriculture. In addition, a more specific insight on natural resources is obtained by considering the duration of the rainy season, the climatic changes in the last 20 years, the features of the vegetation cover in the different seasons and the water resources, both surface and groundwater. 
This set of data aims at the identification of the main vulnerabilities of the local population, allowing for proper territorial planning and sustainable management of the resources by means of the development of correct interventions for the improvement of the territory. These data represent, indeed, the first step to the creation of specific plans of territorial development and improvement of local communities, both at the regional and local scales. Based on the described results, a "Plan of Municipal Development" will be prepared for each of the 31 municipalities of the region, emphasizing the main vulnerabilities of the municipal territory and assessing the priority of the interventions to be realized. In the framework of the RIMRAP project, part of the funds have already been dedicated to the execution of interventions considered as urgent or priority on the basis of the collected information. These interventions mainly involve the management of water (e.g., construction or repair of dams and other surface water infrastructure, water well fixing) and food security (with the construction or improvement of cereal banks).

The general overview of the region provided by this study creates the conditions for a more thoughtful and risk-informed decision-making process, bringing an improvement of the local economy, population welfare and accessibility to natural resources and human infrastructure.

Supplementary Materials: The following are available online at http://www.mdpi.com/2071-1050/12/12/5114/s1. File S1: Survey on the municipalities; File S2: Survey on the communities; File S3: File on the water wells.

Author Contributions: Conceptualization: S.B., S.M.R.B., and D.A.D.L.; methodology: S.B., M.L., S.M.R.B., and L.P.; investigation: S.B., S.M.R.B., and M.L.; formal analysis: A.B. and C.C.; writing-original draft preparation: C.C.; writing-review and editing: S.B., M.L., S.M.R.B., A.B., and L.P.; visualization: C.C., A.B., and L.P. All authors have read and agreed to the published version of the manuscript.

Funding: This research was funded by the European Project "Renforcement Institutionnel en Mauritanie vers la Résilience Agricole et Pastorale" (RIMRAP)—Financement de la Commission Européenne: 11e Fonds européen de développement. Référence: FED/137269/ACT/MR — Contract n ${ }^{\circ}$ FED/2016/373-942: “Reduction de la vulnérabilité Agropastorale et amélioration de la résilience dans le Hodh de Chargui".

Acknowledgments: The authors desire to thank Terre Solidali Onlus for the useful contribution in the onsite activities.

Conflicts of Interest: The authors declare no conflict of interest.

\section{References}

1. Bonetto, S.M.R.; De Luca, D.A.; Lasagna, M.; Lodi, R. Groundwater distribution and fluoride content in the west arsi zone of the oromia region (Ethiopia). In Engineering Geology for Society and Territory; Springer Science and Business Media LLC: Cham, Switzerland, 2014; Volume 3, pp. 579-582.

2. Lasagna, M.; Dino, G.A.; Perotti, L.; Spadafora, F.; De Luca, D.A.; Yadji, G.; Dan-Badjo, A.T.; Moussa, I.; Harouna, M.; Konaté, M.; et al. Georesources and environmental problems in niamey city (Niger): A preliminary sketch. Energy Procedia 2015, 76, 67-76. [CrossRef]

3. Perotti, L.; Dino, G.A.; Lasagna, M.; Moussa, K.; Spadafora, F.; Yadji, G.; Dan-Badjo, A.T.; De Luca, D.A. Monitoring of urban growth and its related environmental impacts: Niamey case study (Niger). Energy Procedia 2016, 97, 37-43. [CrossRef]

4. Bonetto, S.M.R.; Facello, A.; Cristofori, E.I.; Camaro, W.; Demarchi, A. An approach to use earth observation data as support to water management issues in the ethiopian rift. In Climate Change Management; Springer Science and Business Media LLC: Cham, Switzerland, 2017; Volume 316, pp. 357-374.

5. Fonjong, L.N.; Emmanuel, N.N.; Fonchingong, C.C. Rethinking the contribution of indigenous management in small-scale water provision among selected rural communities in Cameroon. Environ. Dev. Sustain. 2005, 6, 429-451. [CrossRef]

6. Del Amo-Rodríguez, S.; Tenorio, M.D.C.V.; Ramos-Prado, J.M.; Porter-Bolland, L. Community landscape planning for rural areas: A model for biocultural resource management. Soc. Nat. Resour. 2010, 23, 436-450. [CrossRef] 
7. Bechis, S.; Bonetto, S.M.R.; Bucci, A.; Canone, D.; Isotta Cristofori, E.; De Luca, D.A.; Demarchi, A.; Garnero, G.; Guerreschi, P.; Lasagna, M.; et al. Improving governance of access to water resources and their sustainable use in Hodh el Chargui communities (South East Mauritania). In Proceedings of the EGU General Assembly Conference Abstracts, Vienna, Austria, 4-13 April 2018.

8. Ghiglieri, G.; Carletti, A. Integrated approach to choosing suitable areas for the realization of productive wells in rural areas of sub-Saharan Africa. Hydrol. Sci. J. 2010, 55, 1357-1370. [CrossRef]

9. Tiepolo, M.; Bacci, M.; Braccio, S.; Bechis, S. Multi-hazard risk assessment at community level integrating local and scientific knowledge in the Hodh Chargui, Mauritania. Sustainability 2019, 11, 5063. [CrossRef]

10. Demarchi, A.; Bechis, S.; Perotti, L.; Garnero, G.; Isotta Cristofori, E.; Alunno, L.; Facello, A.; Semita, C.; Bonetto, S.M.R.; Guerreschi, P.; et al. An interdisciplinary approach to the analysis of agro pastoral resilience in the Hodh el Chargui region (Mauritania). In Proceedings of the EGU General Assembly Conference Abstracts, Vienna, Austria, 4-13 April 2018.

11. Friedel, M.J. Inventory and review of existing PRISM hydrogeologic data for the Islamic Republic of Mauritania, Africa; Open File Report 2008-1138; U. S. Geological Survey: Reston, VA, USA, 2008.

12. Zhang, H.K.; Roy, D.P.; Yan, L.; Li, Z.; Huang, H.; Vermote, E.; Skakun, S.; Roger, J.-C. Characterization of Sentinel-2A and Landsat-8 top of atmosphere, surface, and nadir BRDF adjusted reflectance and NDVI differences. Remote Sens. Environ. 2018, 215, 482-494. [CrossRef]

13. Yang, L.; Meng, X.; Zhang, X. SRTM DEM and its application advances. Int. J. Remote Sens. 2011, 32, 3875-3896. [CrossRef]

14. USGS the Shuttle Radar Topography Mission (SRTM) Collection User Guide. 2015. Available online: https://lpdaac.usgs.gov/documents/179/SRTM_User_Guide_V3.pdf (accessed on 25 May 2020).

15. Radwan, F.; Alazba, A.; Mossad, A. Watershed morphometric analysis of Wadi Baish Dam catchment area using integrated GIS-based approach. Arab. J. Geosci. 2017, 10, 256. [CrossRef]

16. Lai, Z.; Li, S.; Lv, G.; Pan, Z.; Fei, G. Watershed delineation using hydrographic features and a DEM in plain river network region. Hydrol. Process. 2015, 30, 276-288. [CrossRef]

17. Liu, X.; Wang, N.; Shao, J.; Chu, X. An automated processing algorithm for flat areas resulting from DEM Filling and interpolation. ISPRS Int. J. Geo Inf. 2017, 6, 376. [CrossRef]

18. Djokic, D.; Ye, Z.; Dartiguenave, C. Arc Hydro Tools Overview, Version 2.0; ESRI Press: Redlands, CA, USA, 2011.

19. Arc Hydro Geoprocessing Tools-Tutorial-Version 2.0; ESRI Press: Redlands, CA, USA, 2011.

20. Congedo, L. Semi-automatic classification plugin documentation. Release 2016, 4, 29.

21. Ghiraldi, L.; Giordano, E.; Perotti, L.; Giardino, M. Digital tools for collection, promotion and visualisation of geoscientific data: Case study of seguret valley (Piemonte, NW Italy). Geoheritage 2014, 6, 103-112. [CrossRef]

22. Giuffrida, S.; Gagliano, F.; Giannitrapani, E.; Marisca, C.; Napoli, G.; Trovato, M.R. Promoting research and landscape experience in the management of the archaeological networks. A project-valuation experiment in Italy. Sustainability 2020, 12, 4022. [CrossRef]

23. Dan-Badjo, A.T.; Diadie, H.O.; Bonetto, S.M.R.; Semita, C.; Cristofori, E.I.; Facello, A. Using improved varieties of pearl millet in rainfed agriculture in response to climate change: A case study in the tillabéri region in Niger. In Climate Change Research at Universities; Springer International Publishing: Cham, Switzerland, 2017; pp. 345-358.

24. World Health Organization (WHO). Drinking Water Parameter Cooperation Project. Support to the Revision of Annex I Council Directive 98/83/EC on the Quality of Water Intended for Human Consumption (Drinking Water Directive); WHO: Geneva, Switzerland, 2017.

25. Agriculture and Food. Water Quality for Livestock. Available online: https://www.agric.wa.gov.au/livestockbiosecurity/water-quality-livestock (accessed on 15 May 2020).

(C) 2020 by the authors. Licensee MDPI, Basel, Switzerland. This article is an open access article distributed under the terms and conditions of the Creative Commons Attribution (CC BY) license (http://creativecommons.org/licenses/by/4.0/). 